\title{
Sold und schaden: Der Kaiser rechnet ab. Überlegungen zu zwei Schiedsverfahren zwischen Kaiser Friedrich III. und Soldunternehmern zur Zeit des Ungarnkrieges
}

\author{
Sold und schaden. Reflections on two Arbitration Proceedings \\ between Emperor Frederick III. and Leaders of Mercenary Soldiers \\ during the Austro-Hungarian War
}

Petra Heinicker / petra.heinicker@bbaw.de

Berlin-Brandenburgische Akademie der Wissenschaften, Berlin, DE

\begin{abstract}
The arbitration proceedings that took place in 1482 represent the lowest point in the relationships between Frederick III and two of his most important mercenary captains at the time. While the mercenaries claimed for promised pay and damages, Frederick III sued for damages caused by the mercenaries while in his service.

The analysis of the court records highlights how both important and complex the role of scribality was in the process of conflict resolution. It both extended and constricted the scope of action, enabled arguments to be posed and debated, lent structure to legal proceedings, and was itself a matter of concern in the trial.

Opting to resolve conflicts through arbitration was not necessarily a given, for Frederick III as a party rarely took part in such proceedings. This case study, however, demonstrates how in certain circumstances the Emperor perceived abitration as an effective means to an end.
\end{abstract}

\section{Key words}

Frederick III.; Matthias Corvinus; Austro-Hungarian War; Mercenaries; Arbitration Proceedings; Scribality; Conflict Resolution 
Im Januar 1482 fanden in Wien zwei Schiedsverfahren zwischen Kaiser Friedrich III. und mehreren Soldunternehmern statt, die er mit ihren Truppen für den Krieg gegen König Matthias von Ungarn angeworben hatte. ${ }^{1}$ In dem ersten der beiden Verfahren stand dem Kaiser einer seiner obersten Hauptleute, der böhmische Adelige Václav Vlček von Čenov, gegenüber, in dem anderen war es der Söldnerführer Andreas von Weispriach zu Kobelsdorf in Vertretung von etwa zwanzig Rottmeistern. ${ }^{2}$ Die Soldunternehmer hatten 1481 für den Kaiser mehrere Züge zur Abwehr ungarischer Truppen vor allem in der Steiermark und in Niederösterreich unternommen, für die sie ihren Sold sowie Schadenersatz forderten. Der Kaiser hingegen erhob gegen Vlček und Weispriach schwere Vorwürfe, die sich von Ungehorsam über militärische Fehlleistungen bis zur Plünderung kaiserlicher Untertanen spannten, und verlangte von den Söldnern finanzielle Wiedergutmachung für die ihm als Dienst- und Landesherrn entstandenen Schäden. Bis zur Aufnahme der Verfahren waren die Konflikte so weit eskaliert, dass Weispriach und die von ihm vertretenen Rottmeister ihren Dienst quittiert hatten, während Vlček, der mit seinen Söldnern Stetteldorf und weitere Orte im Herzogtum Österreich besetzt hielt, dem Kaiser Fehde angesagt hatte. ${ }^{3}$

Die Protokolle der beiden Schiedsverfahren sind im Wiener Haus-, Hof- und Staatsarchiv im Original überliefert und fallen zunächst aufgrund ihrer äußeren Merkmale ins Auge: Es handelt sich um gut erhaltene Pergamentlibelle mit den anhängenden, nahezu unversehrten Siegeln der jeweiligen Schiedskommission. In über 4.000 bzw. 12.000 Wörtern bannen die Urkunden den Verlauf der beiden Verfahren, die nacheinander im Abstand von zehn Tagen geführt wurden. ${ }^{4}$ Die Protokolle mit den detailreichen, durch-

1 Siehe Protokoll des Schiedsverfahrens zwischen Kaiser Friedrich III. und Václav Vlček von 1482 Januar 14, überliefert in zwei Ausfertigungen im Haus-, Hof- und Staatsarchiv Wien (= HHStA), AUR sub dat., vgl. dazu Regesta chronologico-diplomatica Friderici III. Romanorum Imperatoris (Regis IV.). Bearb. von Joseph Chmel. Wien 1838-1840 (= CHMEL), Nr. 7518 (mit falschem Urkundeninhalt); Protokoll des Schiedsverfahrens zwischen Kaiser Friedrich III. und Andreas von Weispriach von 1482 Januar 23 im HHStA, AUR sub dat., siehe dazu CHMEL, Nr. 7519. Sofern nicht anders angegeben liegen der folgenden Darstellung diese beiden Verfahrensprotokolle zugrunde. - Die ältere Landesgeschichtsschreibung beschäftigte sich am Rande mit den beiden Konfliktfällen, siehe Kurz, Franz: Oesterreich unter Kaiser Friedrich dem Vierten. Band 2. Wien 1812, S. 168-169; Muchar, Albert von: Geschichte des Herzogthumes Steiermark. Band 8. Graz 1867, S. 122-124; Schober, Karl: Die Eroberung Niederösterreichs durch Matthias Corvinus in den Jahren 1482-1490. Wien 1879, S. 13-14, 26-27; Vancsa, Max: Geschichte Nieder- und Oberösterreichs. Zweiter Band 1283-1522. Stuttgart-Gotha 1927, S. 512.

2 Zu Václav Vlček von Čenov und Andreas von Weispriach siehe S. 64-65. Die mitgewondten des letzteren, deren Namensteile sich nicht alle eindeutig zuordnen lassen, waren: Wilhelm Pucher, Paul Arnswald, Ulrich Vorstner, Hans Popp von Poppenstein, Gilig Hundt, Nikolesch Strikobsky, Ambros von Piffyn, Bayde [,] Weitschko, Walne, Niklas Schreckenfuchs, Wetzkobsky [,] Slatko, Custos [,] Kysille, Zibser, Hanns Straubinger, Hans Brattner, Martin Reuss, Gross Lenhart Rutzky und Turin.

3 Siehe Regesten Kaiser Friedrichs III. (1440-1493). Nach Archiven und Bibliotheken geordnet. Heft 35: Die Urkunden und Briefe des Österreichischen Staatsarchivs in Wien, Abt. Haus-, Hof- und Staatsarchiv: Allgemeine Urkundenreihe, Familienurkunden und Abschriftensammlungen (1480-1482). Bearb. von Petra Heinicker und Anne-Katrin Kunde. Wien u.a. 2019 (= REGG.F.III. 35), Nr. 206; Unrest, Jakob: Österreichische Chronik. Hg. von K. Großmann. Monumenta Germaniae Historica Scriptores Rerum Germanicarum. Nova series 11. Weimar 1957, S. $121 \S 118$.

4 Weshalb das Verfahren zwischen dem Kaiser und Vlček sehr viel kürzer ausfiel als das gegen Weispriach, ergibt sich aus der folgenden Darstellung. 
aus widersprüchlichen Schilderungen der prozessrelevanten Ereignisse durch die Streitparteien fokussieren wie durch ein Brennglas auf die Kriegsgeschehnisse des Jahres 1481 in der Steiermark und in Österreich unter der Enns. Die Beschreibungen finden passagenweise ihr Gegenstück in der Darstellung des zeitgenössischen Chronisten Jakob Unrest, der in seiner Österreichischen Chronik die Konflikte zwischen Friedrich III. und Václav Vlček bzw. Andreas von Weispriach als markante Ereignisse des Kriegsjahres 1481 heraushebt. ${ }^{5}$

Zugleich bieten die beiden Urkunden, im Besonderen aber das Protokoll des Weispriach-Verfahrens, einen beispielhaften Einblick in Organisation, Verwaltung und Verlauf des Söldnergeschäftes im 15. Jahrhundert, das in den letzten Jahren vor allem durch die Arbeiten Uwe Tresps in den Fokus der Forschung gerückt worden ist. ${ }^{6}$ Die Abwicklung dieses Geschäftes, so geht aus dessen Untersuchungen hervor, war mit einem hohen Maß an Bürokratie und damit auch Schriftlichkeit verbunden. ${ }^{7}$ Wollte ein Soldunternehmer erfolgreich Geschäfte mit dem Krieg machen, so wird deutlich, musste er nicht nur etwas vom Kämpfen, von Armbrüsten, Harnischen und Pferden, sondern ebenso viel von Verträgen, Abrechnungen und Verwaltungsschriftgut verstehen.

Anknüpfend an diese Beobachtungen soll im Folgenden anhand der beiden Schiedsverfahren vom Januar 1482 überlegt werden, welche Funktion Schriftlichkeit in der Konfliktbewältigung zwischen Dienstherrn und Söldnern hatte. Anhand ausgewählter Streitpunkte sollen sowohl Anlage und Struktur der Verfahren sowie die jeweiligen Verhandlungs- bzw. Verteidigungsstrategien der Parteien nachvollziehbar werden. ${ }^{8}$ Dabei interessiert zum einen, welche Rolle das Krieg und Soldgeschäft flankierende pragmatische Schriftgut, also Schadlosbriefe, Musterungslisten, Marschbefehle u.a., in den beiden Verfahren spielte. Zum anderen rücken die Schiedsverfahren mit den ihnen eigenen schriftlichen Formalteilen, wie Schiedsverträgen, Vollmachten, Verfahrensprotokollen u.a., selbst in den Fokus. ${ }^{9}$

5 Siehe Unrest, J.: Österreichische Chronik, S. 116-127 §§ 113-122, hier insbesondere S. 120-121 §§ 117-118.

6 Siehe hier vor allem Tresp, Uwe: Söldner aus Böhmen. Im Dienst deutscher Fürsten: Kriegsgeschäft und Heeresorganisation im 15. Jahrhundert. Krieg in der Geschichte 19. Paderborn u.a. 2004 sowie ders.: Kostenbewusstsein im Krieg? Zur Verwaltung und Finanzierung der Kriegführung deutscher Fürsten im 15. Jahrhundert. In: Kriegskosten und Kriegsfinanzierung in der Antike. Hg. von F. Burrer. Darmstadt 2008, S. 193-209. Vgl. dazu ältere Arbeiten wie die von Frisch, Ernst: Der Übergang vom Lehendienst zum Solddienst in Österreich. Ein Beitrag zur Heeresgeschichte des 14. Jahrhunderts. Wien 1907.

7 Siehe Tresp, U.: Söldner, vor allem S. 259-361.

8 Die Vorstellung der Streitpunkte erfolgt deshalb nur in Auswahl, weil zum einen Vollständigkeit im Hinblick auf die Fragestellung nicht notwendig ist, zum anderen aber auch, weil sich einige Zusammenhänge nur schwer rekonstruieren lassen, da die jeweiligen Argumente der Parteien zu den einzelnen Klagepunkten nicht konzentriert verhandelt werden, sondern die Parteien in ihren teilweise sehr ausführlichen Reden bzw. Gegenreden jeweils auf die Gesamtheit der gegnerischen Klagen eingehen.

9 Zur Praxis der Schiedsgerichtsbarkeit im Spätmittelalter siehe Bader, Karl Siegfried: Das Schiedsverfahren in Schwaben vom 12. bis zum ausgehenden 16. Jahrhundert. In: ders.: Ausgewählte Schriften zur Rechts- und Landesgeschichte 1. Schriften zur Rechtsgeschichte. Ausgewählt und hg. von C. Schott. Sigmaringen 1984, S. 157-225; Most, Ingeborg: Schiedsgericht, Rechtlicheres Rechtgebot, Ordentliches Gericht, Kammergericht. Zur Technik fürstlicher Politik im 15. Jahrhundert. In: Aus Reichstagen des 15. und 16. Jahrhunderts. Festgabe, dargebracht der Historischen Kommission zur Feier ihres 100jährigen Bestehens von den Herausgebern der Deutschen Reichstagsakten. Schriftenreihe der Historischen Kommission bei der Bayerischen 
Dieser systematischen Untersuchung der beiden Urkunden werden einige Überlegungen zum historischen Hintergrund der Verfahren sowie zur Besetzung der Schiedskommission vorangestellt. Dies geschieht zur Kontextualisierung der Quellen sowie zur Annäherung an die Bedeutung der Schiedsverfahren und ist zugleich verbunden mit der Frage, weshalb diese überhaupt stattfanden. Die Einsetzung von Schiedsrichtern war zwar eine durchaus übliche Methode zur Konfliktbewältigung im Rahmen des Söldnergeschäftes, ${ }^{10}$ und auch Friedrich III. stand der Schiedsgerichtsbarkeit grundsätzlich aufgeschlossen gegenüber, ${ }^{11}$ doch sind bislang nur wenige Fälle bekannt, in denen der Kaiser selbst als Prozesspartei in einem Schiedsverfahren auftrat. ${ }^{12}$ Der Habsburger lehnte dies in einem Fall sogar dezidiert ab mit dem Hinweis, er unterwerfe sich nicht einem Urteilsspruch seiner Untertanen. ${ }^{13}$ Diese Distanz Friedrichs III. gegenüber der Schiedsgerichtsbarkeit zur Lösung eigener Konflikte wirft ein besonderes Licht auf die beiden Verfahren vom Januar 1482, umso mehr, als rasch deutlich wird, dass sie vom kaiserlichen Hof selbst angestoßen worden waren. Vor diesem Hintergrund drängt sich die Vermutung auf, dass die beiden Schiedsverfahren - samt ihrer Schriftlichkeit - für den Kaiser einen bestimmten Zweck erfüllten, den es im Folgenden näher zu konkretisieren gilt.

Im Jahr 1477 waren die Auseinandersetzungen zwischen Kaiser Friedrich III. und Matthias Corvinus um ihre Herrschaftsansprüche in Ungarn, Böhmen und im Herzogtum Österreich in einen offenen Krieg ausgebrochen. ${ }^{14}$ Trotz des noch im selben Jahr ge-

Akademie der Wissenschaften 5. Göttingen 1958, S. 116-153; Krause, Hermann: Die geschichtliche Entwicklung des Schiedsgerichtswesens in Deutschland. Berlin 1930.

10 Siehe Tresp, U.: Söldner, S. 327-329.

11 Ich danke an dieser Stelle Daniel Luger (Wien) für die Einsichtnahme in seinen noch nicht veröffentlichen Aufsatz Zwischen kaiserlichem Befehl und Wunsch der Parteien: zur Einsetzung von Schiedsgerichten unter Kaiser Friedrich III., der in Kürze in den Blättern für deutsche Landesgeschichte erscheinen wird.

12 Bei diesen Fällen aus den Jahren 1440, 1446 und 1458 handelte es sich jeweils um die Beilegung innerhabsburgischer Familienangelegenheiten, siehe Regesten Kaiser Friedrichs III. (1440-1493). Nach Archiven und Bibliotheken geordnet. Heft 12. Die Urkunden und Briefe des Österreichischen Staatsarchivs in Wien, Abt. Haus-, Hof- und Staatsarchiv: Allgemeine Urkundenreihe, Familienurkunden und Abschriftensammlungen (1440-1446). Bearb. von Thomas Willich. Wien u.a. 1999 (= REGG.F.III. 12), Nr. 1 und 316 sowie Copey-Buch der gemainen Stat Wienn, 1454-1464. Hg. von H. J. Zeibig. Fontes Rerum Austriacarum II/7. Wien 1853 (= COPEY-BUCH), S. 149-150, Nr. E.27.a. und E.27.b. Für den Hinweis auf die letztgenannten beiden Urkunden danke ich herzlich Frau Kornelia Holzner-Tobisch (Wien). - Nicht immer lässt sich eindeutig klären, ob es sich bei der Vermittlung durch Dritte um „echte“ Schiedsverfahren handelte, wie z.B. bei der 1464 versuchten Schlichtung des Streits zwischen Friedrich III. und seinem Hauptmann Zdeněk von Sternberg durch den König von Böhmen, siehe Vancsa, M.: Geschichte Nieder- und Oberösterreichs, S. 406-407 und 472.

13 Der Graf von Görz hatte Friedrich III. 1449 vorgeschlagen, ihre Differenzen vor einem, je nach Wunsch des Königs, mit den Herzögen von Bayern, dem Erzbischof von Salzburg oder mit Kurfürsten besetzten Schiedsgericht auszutragen, siehe Regesten Kaiser Friedrichs III. (1440-1493). Nach Archiven und Bibliotheken geordnet. Heft 13. Die Urkunden und Briefe des Österreichischen Staatsarchivs in Wien, Abt. Haus-, Hof- und Staatsarchiv: Allgemeine Urkundenreihe, Familienurkunden und Abschriftensammlungen (1447-1457). Bearb. von Paul Herold und Kornelia Holzner-Tobisch. Wien u.a. 2001 (= REGG.F.III. 13), Nr. 153. Siehe dazu auch künftig Luger, D.: Zwischen kaiserlichem Befehl.

$14 \mathrm{Zu}$ dem Konflikt siehe unter anderen Nehring, Karl: Matthias Covinus, Kaiser Friedrich III. und das Reich. Zum hunyadisch-habsburgischen Gegensatz im Donauraum. Südosteuropäische Arbeiten 72. München 
schlossenen Friedens und wiederholter Waffenstillstandsverträge rissen in den darauffolgenden Jahren die militärischen Auseinandersetzungen bis zur erneuten Kriegserklärung des Corvinen an den Kaiser im Frühjahr 1482 nie gänzlich ab. Zwischen 1479 und 1481 war es wiederholt zu Zusammenstößen zwischen ungarischen und kaiserlichern Söldnertruppen gekommen, sowohl in den habsburgischen Erblanden als auch in Ungarn. ${ }^{15}$ Friedrich III. hatte in diesen Jahren den Konflikt noch einmal verschärft, indem er die Ersetzung des amtierenden Salzburger Erzbischofs durch den aus Ungarn geflüchteten Erzbischof von Gran, Johann Beckensloer, vorangetrieben hatte, ${ }^{16}$ den er schließlich als obersten kaiserlichen Hauptmann zum „Organisator"17 des Krieges gegen Matthias Corvinus machte. Durch diesen Krieg wurden auf habsburgischer Seite vor allem die Steiermark und Niederösterreich, im Wesentlichen durch die Züge des in ungarischen Diensten stehenden böhmischen Söldnerführers Jan Zelený von Šanov, in Mitleidenschaft gezogen. ${ }^{18}$ Beide Länder gingen schließlich an Matthias Corvinus verloren.

Als die Konflikte mit Vlček und Weispriach 1481/82 eskalierten, stand Kaiser Friedrich III. nicht allein wegen des Ungarnkonfliktes unter großem politischem, militärischem wie finanziellem Druck. Zu Beginn des neuen Jahrzehnts hatte sich parallel zu den Auseinandersetzungen mit Matthias Corvinus auch die Situation im burgundischniederländischen Erbfolgekrieg verschäft und die Türken drängten in die Steiermark und nach Kärnten. ${ }^{19}$ Im Spannungsfeld dieser politisch-militärischen Konfliktlagen priorisierte der Kaiser ab 1480 die aktive Bewältigung der Ungarnkrise, ${ }^{20}$ fand für einen Krieg gegen Matthias Corvinus jedoch nur wenig Rückhalt im Reich. Die Reichsfürsten drängten lange auf Vermittlung zwischen Kaiser und König und nur wenige der Reichsstände und Reichsstädte kamen der schließlich auf dem Nürnberger Tag 1481 beschlossenen Reichshilfe, die in Form einer kurzfristigen Entsendung von Truppenkontingenten nach Wien erfolgen sollte, nach. ${ }^{21}$

1989², S. 107-193; Isenmann, Eberhard: Kaiserliche Obrigkeit und ständischer Untertanenverband. Untersuchungen zu Reichsdienst und Reichspolitik der Stände und Städte in der zweiten Hälfte des 15. Jahrhunderts. [Universität Tübingen] 1983, S. 312-321; Vancsa, M.: Geschichte Nieder- und Oberösterreichs, S. 499523; Schäffer, Roland: Die Zeit Kaiser Friedrichs III. (1424-1493). In: Die Steiermark im Spätmittelalter. Hg. von G. Pferschy. Geschichte der Steiermark 4. Wien u.a. 2018, S. 43-74, hier S. 62.

15 Siehe Hoensch, Jörg K.: Matthias Corvinus. Diplomat, Feldherr und Mäzen. Graz u.a. 1998, S. 74; Vancsa, M.: Geschichte Nieder- und Oberösterreichs, S. 509-510.

16 Siehe Heinig, Paul-Joachim: Kaiser Friedrich III.: Hof, Regierung und Politik, Bde. 1-3. Forschungen zur Kaiser- und Papstgeschichte des Mittelalters. Beihefte zu J. F. Böhmer, Regesta Imperii 17. Köln u.a. 1997, S. 450; zum Streit um den Salzburger Erzstuhl siehe auch Dopsch, Heinz: Salzburg im 15. Jahrhundert. In: Geschichte Salzburgs. Stadt und Land 1. Vorzeit, Altertum, Mittelalter. Hg. von H. Dopsch. Salzburg 1981, S. 487-593.

17 Siehe Heinig, P.-J.: Kaiser Friedrich III., S. 451; vgl. dazu Nehring, K.: Matthias Corvinus, S. 150.

18 Zu Zelený siehe Nehring, K.: Matthias Corvinus, S. 150; Vancsa, M.: Geschichte Nieder- und Oberösterreichs, S. 509-510; Hoensch, J. K.: Matthias Corvinus, S. 164.

19 Siehe Isenmann, E.: Kaiserliche Obrigkeit, S. 355.

20 Siehe ebenda.

21 Siehe Nehring, K.: Matthias Corvinus, S. 137-149 sowie Isenmann, E.: Kaiserliche Obrigkeit, S. 387-401. 
Parallel zu dieser politischen Isolierung geriet der Kaiser zunehmend in finanzielle Bedrängnis. Der Erbfolgekrieg musste ebenso finanziert werden wie die burgundische Hochzeit seines Sohnes Maximilian, und auch die 100.000 Goldgulden, die Friedrich III. laut Friedensvertrag von 1477 Matthias Corvinus als Kriegsentschädigung zu leisten hatte, waren noch nicht bezahlt. ${ }^{22}$ Nicht zuletzt aber verschlangen die Truppen, die der Kaiser zur Verteidigung seiner Erblande gegen die Türken und die Ungarn angeworben hatte und zu denen auch diejenigen Vlčeks und Weispriachs zählten, immense Summen. ${ }^{23}$

Friedrich III. hatte sich in seiner Regierungszeit immer wieder mit eigenen Söldnern auseinanderzusetzen, die ihn angriffen, seine Untertanen ausplünderten oder die Partei wechselten. ${ }^{24}$ Doch vor dem Hintergrund der für ihn so prekären Lage 1481/82, in welcher er nahezu ohne Truppen, Geld und Rückhalt aus dem Reich dastand, wirkten die Konflikte mit Vlček und Weispriach besonders destabilisierend, ${ }^{25}$ nicht zuletzt weil es sich bei ihnen nicht, wie noch in der älteren Literatur angenommen, um „kleinere Rottenführer", ${ }^{26}$ sondern um zwei seiner wichtigsten Söldnerführer handelte.

Václav Vlček von Čenov gilt als der ,angesehenste böhmische Söldnerführer seiner Zeit“, ${ }^{27}$ der über jahrzehntelange Erfahrung im Kriegsgeschäft verfügte und bereits wiederholt in habsburgischen Diensten gestanden hatte. Friedrich III. hatte ihm als einem seiner obersten Hauptleute an der Seite Johann Beckensloers mit dem Entsatz von Marburg (Maribor) die Verantwortung für eine der wichtigsten militärischen Operationen des Jahres 1481 übertragen. ${ }^{28}$ Doch der erfahrene Kriegsmann konnte seinem Dienstherrn gleichermaßen nützlich wie gefährlich sein. Im Jahr 1465 hatte Vlček schon einmal eine Schar unbezahlter Söldner in einer bruderschaft um sich versammelt, dem Kaiser Fehde angesagt und diesen so zur Zahlung ausstehenden Soldes erpresst. ${ }^{29}$ Wie groß die Bruderschaft Vlčeks im Jahr 1482 war, ist nicht genau zu ermitteln. Möglicherweise handelte es sich um die zwischen 2.000 bis 3.000 Mann, mit denen er dem Chronisten Unrest zufolge von einem nicht autorisierten, von Johann Beckensloer befohlenen Zug nach Ungarn zurückgekehrt war. ${ }^{30}$

22 Siehe Vancsa, M.: Geschichte Nieder- und Oberösterreichs, S. 501 und 504.

23 Im Sommer 1480 z.B. hatte der Kaiser mehreren Rottmeistern für Sold und Schadenersatz die Zahlung von über 13.000 Pfd. Pf. zusichern müssen, siehe Regesten Kaiser Friedrichs III. (1440-1493). Nach Archiven und Bibliotheken geordnet. H. 10: Die Urkunden und Briefe aus den Archiven und Bibliotheken des Landes Thüringen. Bearb. von Eberhard Holtz. Wien u.a. 1996 (= REGG.F.III. 10), Nr. 471; siehe auch Vancsa, M.: Geschichte Nieder- und Oberösterreichs, S. 504.

24 Siehe Beispiele bei Vancsa, M.: Geschichte Nieder- und Oberösterreichs, S. 408-409 und Dopsch, H.: Salzburg, S. 550-551.

25 Vgl. dazu Dopsch, H.: Salzburg, S. 551.

26 Siehe Vancsa, M.: Geschichte Nieder-und Oberösterreichs, S. 512.

27 Zu Vlček siehe Tresp, U.: Söldner, S. 51, 64-66, 108-109, 115, 118, hier S. 115.

28 Vgl. dazu Dopsch, H.: Salzburg, S. 551 und Schäffer, R.: Zeit Kaiser Friedrichs III., S. 62.

29 Allgemein zu den Bruderschaften (Bratríci) siehe Tresp, U.: Söldner, S. 59-69, zu Vlček siehe ebenda, S. 64-65.

30 Der Chronist berichtet, dass Vlček und der Erzbischof von Gran nach dem Entsatz von Marburg einen erfolglosen Zug nach Ungarn unternahmen, bei dem Vlček 3.000 berittene Söldner unterstanden hätten, 
Andreas von Weispriach wiederum stammte aus einer dem Kaiserhof nahestehenden Kärntner Familie. ${ }^{31}$ Bevor er von Friedrich III. zur Abwehr ungarischer Truppen in die Steiermark abbefohlen worden war, ${ }^{32}$ hatte er neben seinem Bruder und dem landesfürstlichen Pfleger Leonhard Kollnitzer bereits in Kärnten eine führende Funktion in der Landesverteidigung innegehabt. ${ }^{33}$ Bei den Zügen in die Steiermark fungierte Weispriach unter den von ihm vertretenen Rottmeistern anscheinend als eine Art primus inter pares. ${ }^{34}$ Seinen eigenen Aussagen zufolge hatte er während der Züge keine Befehlsgewalt über alle vom Verfahren betroffenen Dienstleute gehabt, hatte jedoch wiederholt die Rottmeister gegenüber den Feldhauptleuten bzw. dem obersten Hauptmann Johann Beckensloer und dem Kaiser vertreten bzw. zwischen den Parteien vermittelt und in prekären Situationen die Führung übernommen. ${ }^{35}$ Ansonsten hatten Weispriach und die anderen Rottmeister im Verlauf der im Verfahren verhandelten Zeit dem Befehl verschiedener kaiserlicher Feldhauptleute unterstanden, das waren u.a. Jörg von Wolframsdorf, der zum Zeitpunkt des Prozesses bereits verstorbene Jörg Reichenburger sowie kurzzeitig auch Václav Vlček. Die Zahl der Söldner, die Weispriach aus Kärnten in die Steiermark führte, beziffert Unrest auf mehrere hundert. ${ }^{36}$ Die Gesamtzahl der Söldner, die hinter den von Weispriach vertretenen Rottmeistern standen, dürfte allerdings weitaus größer gewesen sein. Im Kampf um das steirische Neumarkt, so berichten fünf der Rottmeister während des Verfahrens, hätten sie mit 1.400 Mann einer ungarischen Übermacht von 2.500 Söldnern gegenübergestanden. ${ }^{37}$

Die Schiedsverfahren waren offensichtlich relativ kurzfristig anberaumt worden, nachdem zumindest mit Vlček bereits im Vorfeld Verhandlungen geführt worden waren. ${ }^{38}$ Ein Initiator hinter den Schiedsverfahren dürfte in Sigmund Prüschenk zu suchen sein, der

von denen während des Zuges 1.000 gestorben seien, siehe Unrest, J.: Österreichische Chronik, S. $121 \S 118$.

31 Zum Herrscherdienst der Weispriach siehe Heinig, P.-J.: Kaiser Friedrich III., S. 222-225, zu Andreas siehe S. 223-224.

32 Unrest zufolge hatte der Kaiser Andreas von Weispriach mit seinen Truppen relativ bald nach der von den Reichsfürsten initiierten Vermittlungsmission zwischen Friedrich III. und Matthias Corvinus durch den Bischof von Eichstätt aus Kärnten abgezogen, möglicherweise also bereits in der zweiten Februarhälfte 1481, siehe Unrest, J.: Österreichische Chronik, S. 119-120 §§ 116-117, vgl. dazu Nehring, K.: Matthias Corvinus, S. 138.

33 Siehe Unrest, J.: Österreichische Chronik, S. $107 \S 104$ sowie S. 108-109 § 106.

34 Es lässt sich nicht eindeutig feststellen, ob es zwischen den Rottmeistern hierarchisch abgestufte Verhältnisse bzw. irgendwelche Subkontrakte gab, zu solchen siehe Tresp, U.: Söldner, S. 444.

35 Aus Weispriachs Aussagen geht z.B. hervor, dass die Rottmeister nach seinen Vermittlungsbemühungen bereit gewesen seien, trotz des ausstehenden Soldes weiterhin in der Steiermark zu bleiben, und als sie bei dem steirischen Knittelfeld mit ihren Truppen in eine gefährliche Lage geraten seien, sei er aus phlicht als ain hawbtman(n) mit den gut(e)n lewten heraus gezogen.

36 Siehe Unrest, J.: Österreichische Chronik, S. $120 \S 117$.

37 Neumarkt war seit dem Sommer 1480 von ungarischen Truppen besetzt gewesen, siehe Dopsch, H.: Salzburg, S. 549-550.

38 Vlček zufolge hatten ihm die Verhandler auch eine Teilsumme in Höhe von 2.000 Pfd. Pf. ausbezahlt, von den dann im Schiedsverfahren erhobenen Anklagen des Kaisers aber hätten sie erst wenige Tage vor Prozessbeginn erfahren. 
gemeinsam mit dem Kämmerer Kaspar von Roggendorf ${ }^{39}$ die Schiedsverträge zwischen dem Kaiser und den Soldunternehmern ausgehandelt hatte. Prüschenk, zur Zeit der Verfahren Kammermeister und Rat Friedrichs III. und ab Sommer 1482 Hofmarschall, war seit dem erneuten Ausbruch des Ungarnkrieges zu einem der wichtigsten Geldgeber und engsten Vertrauten des Kaisers und damit zu einem der einflussreichsten Männer am kaiserlichen Hof überhaupt avanciert. ${ }^{40} 1481$ hatte er eine zentrale Funktion bei der kaiserlichen Truppenorganisation inne, bestimmte die Löhne der Söldner, die Laufzeit und Bedingungen der Soldverträge und wickelte die Bezahlung der Söldner ab. ${ }^{41}$ Friedrich III., der weder über ausreichend Truppen noch Geld verfügte, war, so Paul-Joachim Heinig, „von derartigem Großunternehmertum an seinem Hof abhängig. “42 Prüschenk dürfte also Anfang des Jahres 1482 nicht nur den besten Überblick über die aktuellen Kosten des Ungarnkrieges, sondern im Hinblick auf sein finanzielles Engagement auch ein persönliches Interesse an einem für den Kaiser positiven Ausgang der Konflikte mit Vlček und Weispriach gehabt haben. ${ }^{43}$

Als Schiedsrichter fungierten fünf kaiserliche Räte sowie fünf Räte bzw. Hauptleute von Reichsfürsten, die Friedrich III. zu dieser Zeit gegen Matthias Corvinus unterstützten, das waren der Pfalzgraf bei Rhein, die Herzöge von Sachsen, der Markgraf von Brandenburg sowie die Bischöfe von Bamberg und Würzburg. ${ }^{44}$ Auch die Schadenermittlung im Rahmen einer gütlichen Einigung übertrug Friedrich III. in der Regel seinen Räten, ${ }^{45}$ Söldner mit mehr Verhandlungsgeschick konnten die Hinzuziehung neutralerer Gut-

39 Zu dem mit Prüschenk verwandten Roggendorfer, der seinen Beitrag zur Verteidigung der Erblande mit der Abwehr ungarischer Truppen vor Krems und Stein im Jahr 1477 geleistet hatte, siehe Zajic, Andreas: Kaspar von Roggendorf (gest. 1506). Karrierist und Kunstliebhaber. In: Waldviertler Biographien, Band 2. Hg. von H. Hitz u.a. Horn, Waidhofen/Thaya 2004, S. 9-32, hier S. 14-15.

40 Zum Herrscherdienst Prüschenks siehe Heinig, P.-J.: Kaiser Friedrich III., S. 78-88 und 92, zu Prüschenks Aufstieg und Funktion während des Ungarnkrieges siehe ebenda, S. 79-81; vgl. dazu Probszt, Günter: Die Brüder Prueschenk. Oberösterreichische Heimatblätter 14, 1960, S. 115-127.

41 Siehe Heinig, P.-J.: Kaiser Friedrich III., S. 81; REGG.F.III. 35, Nr. 152 und Nr. 205; sowie Regesten Kaiser Friedrichs III. (1440-1493). Nach Archiven und Bibliothek geordnet. Heft 30. Die Urkunden und Briefe des Österreichischen Staatsarchivs in Wien, Abt. Haus-, Hof- und Staatsarchiv: Allgemeine Urkundenreihe, Familienurkunden und Abschriftensammlungen (1483-1488). Bearb. von Peter Gretzel. Wien u.a. 2014 (= REGG.F.III. 30), Nr. 10.

42 Siehe Heinig, P.-J.: Kaiser Friedrich III., S. 81.

43 Ob sich der Kaiser auch selbst, wie es andere deutsche Fürsten am Ende des Mittelalters zunehmend taten, aktiv mit den Kosten von Kriegen auseinandersetzte, wie Tresp, U.: Kostenbewusstsein, S. 204 aufzeigt, wäre zu untersuchen.

44 Die Herzöge von Sachsen und der Brandenburger gehörten zu den ersten und wenigen Fürsten, die 1481 bereit gewesen waren, dem Kaiser Hilfskontingente gegen den Corvinen zu senden, siehe Nehring, K.: Matthias Corvinus, S. 145-149.

45 Siehe REGG.F.III. 10, Nr. 472 sowie Regesten Kaiser Friedrichs III. (1440-1493). Nach Archiven und Bibliotheken geordnet. Heft 32. Die Urkunden und Briefe aus dem Staatsarchiv Bamberg und den Archiven und Bibliotheken des Regierungsbezirks Oberfranken sowie aus dem Bestand Rep. 106a (Fehdeakten) des Staatsarchivs Nürnberg. Bearb. von Elfie-Marita Eibl. Wien u.a. 2018 (= REGG.F.III. 32), Nr. 85, 97, 86, 104-105. 
achter erwirken. ${ }^{46}$ Im Söldnergeschäft war es allgemein üblich, Räte oder Hauptleute des Kriegsherrn für die Schadenermittlung bzw. als Schiedsrichter zur Schlichtung von Streitigkeiten zu bestimmen, ${ }^{47}$ d.h. eine paritätische Besetzung oder gar Unabhängigkeit einer Schiedskommission war von Seiten des Dienstherrn weder im Allgemeinen noch in den vorliegenden Fällen angestrebt. ${ }^{48}$

Entsprechend achtete der Hof im Januar 1482 bei der Zusammenstellung der Schiedsrichter darauf, dass sich Sachkompetenz, Prozesserfahrung und Nähe zum Kaiser sinnvoll ergänzten. Die Schiedskommission versammelte eine ganze Anzahl von Ungarnspezialisten des Hofes und mit ihnen einige der bedeutendsten Räte des Kaisers überhaupt. Das waren der wahrscheinlich während des Ungarnkrieges in kaiserlichen Dienst getretene und bereits 1480/81 fallweise als Schieds- bzw. Kammerrichter tätige Georg von Eckartsau, ${ }^{49}$ der oberste Kämmerer von Österreich Veit von Ebersdorf, ${ }^{50}$ der einer herrschernahen Familie aus Österreich ob der Enns entstammende Ulrich von Starhemberg, ${ }^{51}$ ferner der am Hof äußerst einflussreiche langjährige Protonotar der österreichischen Kanzlei Dr. utr. iur. Thomas Prelager von Cilli, welcher ab 1476 in der Hauptaufgabe vom Kaiser mit allen Ungarn betreffenden Angelegenheiten betraut war, ${ }^{52}$ sowie Jörg Kling, der gemeinsam mit dem Kämmerer des böhmischen Königs die erwähnten Vorabverhandlungen mit Vlček geführt hatte, ${ }^{53}$ und schließlich der erfahrene kaiserliche Kammerprokurator-Fiskal Johann Keller, der als „einer der wichtigsten Räte des Kaisers überhaupt“ gilt und bereits in zahlreichen Fiskalprozessen die politischen Interessen des Kaisers durchgesetzt hatte..$^{54}$

Von den fünf nicht-kaiserlichen Räten bzw. Hauptleuten sei zum einen der von den Herzögen von Sachsen zum Kaiser entsandte Hauptmann Sittich von Zedtwitz genannt, ${ }^{55}$ unter dessen Führung zeitweise auch die von Andreas von Weispriach vertretenen Rottmeister gestanden hatten, sowie der pfalzgräfliche Rat und Unterlandvogt der Reichslandvogtei

46 Das konnten z.B. Hauptleute sein, siehe REGG.F.III. 32, Nr. 80-82, oder aber am Schaden unbeteiligte Männer aus den Rotten, siehe REGG.F.III. 32, Nr. 90-92.

47 Vgl. Ettelt-Schönewald, Beatrix: Kanzlei, Rat und Regierung Herzog Ludwigs des Reichen von Bayern-Landshut (1450-1479). Teilband 1. Schriftenreihe zur bayerischen Landesgeschichte 97/1. München 1996, S. 94 und Tresp, U.: Söldner, S. 265 und 327, der darauf hinweist, dass sich Dienstherr und Söldner üblicherweise vor Dienstantritt schriftlich auf Personen einigten, die mögliche Streitfragen klären sollten.

48 Die Hauptleute nahmen mitunter eine Mittlerfunktion zwischen dem Dienstherrn und den Söldnern ein, siehe Tresp, U.: Söldner, S. 248-249.

49 Zu Georg von Eckartsau siehe Heinig, P.-J.: Kaiser Friedrich III., S. 262-263.

50 Die Ebersdorfer stellten über die Jahre mehrere Räte des Kaisers, siehe ebenda, S. 253-254.

51 Siehe ebenda, S. 252-253.

52 Zur Person siehe ebenda, S. 612-618, insbesondere S. 615-616.

53 Zu Kling siehe auch REGG.F.III. 10, Nr. 518.

54 Zu Keller siehe Heinig, P.-J.: Kaiser Friedrich III., S. 123-134, das Zitat siehe S. 123.

55 Die Herzöge von Sachsen hatten dem Kaiser unter der Führung Sittichs von Zedtwitz Truppen zum Kampf gegen die Türken geschickt und später ihre Bereitschaft erklärt, diese gegen Matthias Covinus einzusetzen, siehe Nehring, K.: Matthias Corvinus, S. 138 und 150 sowie Regesten Kaiser Friedrichs III. (14401493). Nach Archiven und Bibliotheken geordnet. Heft 11. Die Urkunden und Briefe aus den Archiven und Bibliotheken des Freistaates Sachsen. Bearb. von Elfie-Marita Eibl. Wien u.a. 1998, (= REGG.F.III. 11), Nr. 519. 
im Elsass, Götz von Adelsheim, der bereits am pfalzgräflichen Hofgericht als Urteiler fungiert hatte und zudem in einem näheren Verhältnis zum Kaiser bzw. zu Prüschenk gestanden zu haben scheint. ${ }^{56}$

Der Kaiser ließ sich in beiden Verfahren von vier Wiener Bürgern vertreten. Neben dem wortführenden Wolfgang Gwerlich, dem späteren Fiskal Kaiser Maximilians I., ${ }^{57}$ ist hier vor allem der langjährige österreichische Hubschreiber Mert Burger zu erwähnen, der, wie aus den Protokollen hervorgeht, für die technische Seite der Abrechnung mit den Söldnern zuständig war. ${ }^{58}$ Während Andreas von Weispriach die Vertretung seiner eigenen Person und der genannten Rottmeister übernahm, sprach für Vlček ein Mitglied seiner Bruderschaft mit Namen Kuntz Stieber, kurz Schwab genannt.

Der kaiserliche Hof ließ nicht nur Sorgfalt bei der Wahl der Schiedsrichter walten, sondern achtete auch darauf, dass die den Verfahren zugrunde liegenden schriftlichen Verträge im Sinne des Kaisers gestaltet waren. Der Schiedsvertrag, in den hier untersuchten Quellen als anlasbrif bezeichnet, ${ }^{59}$ bildete die rechtliche Grundlage eines Schiedsverfahrens. ${ }^{60}$ Diese der Idee nach auf Gegenseitigkeit beruhende Vereinbarung zwischen den Streitparteien beinhaltete in der Regel neben der Nennung der Schiedsrichter auch die Erklärung der Parteien, sich dem Urteil der verwillkürten Richter zu unterwerfen. ${ }^{61}$ In den wenigen bislang bekannten Fällen, in denen sich Friedrich III. auf Schiedsverfahren einließ und bei denen es ausnahmslos um die Beilegung innerhabsburgischer Streitigkeiten ging, gab er auch jeweils eine solche Erklärung ab. ${ }^{62}$ Als er 1458 den österreichischen Ständen den Auftrag erteilte, die Streitigkeiten zwischen ihm, seinem Bruder Albrecht VI. und seinem Vetter Sigmund von Tirol zu entscheiden, versicherte er jenen sogar explizit, dass sie keine Konsequenzen zu fürchten hätten,

56 Ferner gehörten zu dem Schiedsgremium der brandenburgische Rat Niklas Schurntinger, der Bamberger Rat Veit von Giech sowie der Würzburger Rat Christoph Marschall zu Salzburg. Zu Götz von Adelsheim siehe Regesten Kaiser Friedrichs III. (1440-1493). Nach Archiven und Bibliotheken geordnet. Heft 17. Die Urkunden und Briefe aus den Archiven und Bibliotheken der Stadt Speyer. Bearb. von Joachim Kemper. Wien u.a. 2002, (= REGG.F.III. 17), Nr. 291. Adelsheim hatte nur wenige Wochen zuvor über Sigmund Prüschenk vom Kaiser ein Pferd im Wert von 100 ungarischen Gulden erhalten, siehe REGG.F.III. 35, Nr. 152.

57 Zu Gwerlich siehe Böhmer, J. F.: Regesta Imperii XIV. Ausgewählte Regesten des Kaiserreiches unter Maximilian I. 1493-1519. Bd. 2: 1496-1498. Bearb. von Hermann Wiesflecker, unter Mitwirkung von Manfred Hollegger u.a. Köln u.a. 1993, Nr. 7019.

58 Mert Burger bekleidete von 1456 bis 1485 das Amt des Hubschreibers in Österreich, siehe Perger, Richard: Die Wiener Ratsbürger 1396-1526. Ein Handbuch. Forschungen und Beiträge zur Wiener Stadtgeschichte 18. Wien 1988, S. 174, Nr. 65. Bei den beiden anderen Anwälten handelte es sich um den Wiener Ratsherren Niklas Teschler sowie Christoph Rössl, zu Teschler siehe ebenda, S. 185 n. 126.

59 Vgl. dazu REGG.F.III. 12, Nr. 316.

60 Zur Gestaltung und rechtlichen Bedeutung des Schiedsvertrags, auch als Kompromiss bezeichnet, siehe Bader, K. S.: Schiedsverfahren, S. 185-188.

61 Siehe ebenda, S. 185-188; Baumbach, Hendrik: Königliche Gerichtsbarkeit und Landfriedenssorge im deutschen Spätmittelalter. Eine Geschichte der Verfahren und Delegationsformen zur Konfliktbehandlung. Wien u.a. 2017, S. 356-357.

62 Siehe REGG.F.III. 12, Nr. 1 und 316 sowie COPEY-BUCH, S. 149-150, Nr. E.27.a. Vgl. dazu auch künftig Luger, D.: Zwischen kaiserlichem Befehl. 
sollte ihr Urteil nicht in seinem Sinne ausfallen. ${ }^{63}$ Deshalb erscheint es auffällig, dass die beiden in den Verfahrensprotokollen von 1482 inserierten Anlassbriefe zwar fixieren, der anlass sei mit Friedrich III. verhandelt worden, beide Urkunden aber ausschließlich im Namen der jeweiligen Söldnerpartei ausgestellt sind, nicht jedoch im Namen des Kaisers. ${ }^{64}$ Eine Einwilligung in die beiden Schiedsverfahren erfolgte seinerseits nur mittelbar durch die Besiegelung der beiden Urkunden durch seine Räte Prüschenk und Roggendorfer sowie durch das Auftreten seines Anwaltes bzw. seiner eigenen Person vor Gericht. Friedrich III. umging hier wahrscheinlich bewusst eine rechtlich bindende, schriftliche Verpflichtung, sich einem Urteil seiner Untertanen zu unterwerfen. Dies war er in wichtigen familiären Angelegenheiten noch zu tun bereit, nicht aber im Streit mit unebenbürtigen Dienstleuten. Der Grund hierfür dürfte nicht zuletzt in dem ausgeprägt monarchischen Herrschaftsanspruch Friedrichs III. zu suchen sein, ${ }^{65}$ der ihn auch dezidiert auf seiner Rechtsstellung als oberster Richter im Reich beharren ließ. ${ }^{66}$ Diese von ihm mit deutlicherem Nachdruck als von seinen Vorgängern wahrgenommene Funktion als oberster Richter verlieh ihm als Reichsoberhaupt eine integrative Wirkung: Er hatte die Möglichkeit, seine Herrschaft im Reich zu konsolidieren, indem er dieses rechtlich zusammenhielt. ${ }^{67} \mathrm{Zu}$ seinem wichtigsten Werkzeug in diesem Zusammenhang machte Friedrich III. das auf ihn als Reichsoberhaupt und obersten Richter ausgerichtete Kammergericht, ${ }^{68}$ während z.B. das Hofgericht seine Bedeutung verlor. ${ }^{69}$ Im Hinblick auf seinen Herrschaftsanspruch und sein Selbstverständnis dürfte für Friedrich III. also die Wahl eines Schiedsverfahrens als Mittel der Konfliktlösung die ultima ratio und nur ein gangbarer Weg gewesen sein, wenn von vornherein feststand, dass das Urteil seine Autorität als Reichsoberhaupt wahren würde, womit im Hinblick auf die Besetzung der Schiedskommission zu rechnen war. Der Kaiser eröffnete sich mit diesen an seine Bedürfnisse angepassten Schiedsverfahren eine Möglichkeit, sich einen taktischen Vorteil in der für ihn wirtschaftlich sowie, im Hinblick auf die ihn befehdenden Söldner, auch militärisch prekären Lage zu verschaffen.

63 Siehe COPEY-BUCH, S. 150, Nr. E.27.b.

64 Die beiden Urkunden, von denen die Vlčeks auf 1481 Dezember 31 und die Weispriachs auf 1482 Januar 12 datiert, waren den Inserten zufolge auch von den Soldunternehmern besiegelt worden.

65 Heinig, Paul-Joachim: Monarchismus und Monarchisten am Hof Friedrichs III. In: König und Kanzlist, Kaiser und Papst. Friedrich III. und Enea Silvio Piccolomini in Wiener Neustadt. Hg. von F. Fuchs - P.-J. Heinig - M. Wagendorfer. Forschungen zur Kaiser- und Papstgeschichte des Mittelalters 21. Wien u.a. 2013, S. 151-180, hier S. 153.

66 Siehe dazu auch künftig Luger, D.: Zwischen kaiserlichem Befehl.

67 Siehe Diestelkamp, Bernhard: Vom einstufigen Gericht zur obersten Rechtsmittelinstanz. Die deutsche Königsgerichtsbarkeit und die Verdichtung der Reichsverfassung im Spätmittelalter. Quellen und Forschungen zur höchsten Gerichtsbarkeit im Alten Reich 64. Köln u.a. 2014, S. 150-151.

68 Siehe Heinig, Paul-Joachim: Kaiser Friedrich III. und Hessen. In: Hessisches Jahrbuch für Landesgeschichte 32. Marburg 1982, S. 63-101, hier S. 100, und Diestelkamp, B.: Vom einstufigen Gericht, S. 150.

69 Die Gründe für das Verschwinden des Hofgerichts sowie der Weg des Übergangs von der Hof- zur Kammergerichtsbarkeit sind weiterhin Gegenstand der wissenschaftlichen Diskussion, siehe z.B. Diestelkamp, B.: Vom einstufigen Gericht, S. 23-26 sowie Baumbach, H.: Königliche Gerichtsbarkeit, S. 285-298. 
Beide Prozesse folgten dem formalen Ablauf, wie er sich bis ins 15. Jahrhundert für Schiedsverfahren ausgebildet hatte. ${ }^{70}$ Nach dem Abschluss der Schiedsverträge erfolgte an einem darin festgesetzten Tag die Klageerhebung sowie die Klagebeantwortung bzw. Einrede durch die gegnerische Partei, womit die Verfahren offiziell eröffnet waren. ${ }^{71}$ Die formale Klage bildeten in beiden Schiedsverfahren die Forderungen der Söldner auf Sold und Schadenersatz. Faktisch aber standen die in der jeweiligen Einrede des kaiserlichen Anwalts vorgetragenen Vorwürfe Friedrichs III. gegenüber den Söldnern im Mittelpunkt beider Verfahren. Gemäß den Schiedsverträgen sollte am Ende beider Verfahren ein Urteil der Schiedsrichter stehen. Ein solches wurde schließlich auch in beiden Fällen nach Beendigung der Beweisaufnahme von den Schiedsrichtern verkündet. ${ }^{72}$ Zwischen Eröffnung des Verfahrens und Urteil vergingen im Vlček-Prozess neun und im Weispriach-Prozess zehn Tage. Das Ziel der Verfahren, das wird spätestens mit der Verkündigung der Urteile deutlich, war nicht die Ermittlung konkreter Geldsummen. Die Aufgabe der Schiedsrichter bestand vielmehr darin, die Qualität der Beweisgrundlage und mit ihr die Rechtmäßigkeit der Ansprüche beider Parteien zu prüfen. ${ }^{73}$

Dem böhmischen Söldnerführer Václav Vlček von Čenov warf der Kaiser vor, trotz Vorauszahlung auf seinen Sold, den Dienst als Hauptmann nicht ordnungsgemäß ausgeführt zu haben. Die Klagen lauteten auf militärisches Fehlverhalten, ${ }^{74}$ die Schädigung von Landleuten, ${ }^{75}$ die Missachtung gängiger Beutepraxis, Betrug in der Soldabrechnung, ${ }^{76}$ eigenmächtiges Handeln und Nichtbeachtung kaiserlicher Befehle, die Vereinigung mit Rottmeistern und Söldnern gegen den Kaiser, Abschluss eines nicht autorisierten Waf-

70 Siehe Bader, K. S.: Schiedsverfahren, S. 199-206.

71 Siehe ebenda, S. 200. Das Verfahren zwischen dem Kaiser und Vlček wurde am 5. Januar, das gegen Weispriach am 14. Januar 1482 eröffnet.

72 Zum Urteil in Schiedsverfahren siehe ebenda, S. 205-206.

73 Bader zufolge lässt sich anhand der Verträge nicht immer eindeutig klären, ob in einem Streitfall Schiedsrichter oder Schiedsgutachter im Sinne von Sachverständigen bestellt werden. Während ein Schiedsrichter einen Rechtsstreit zu entscheiden hat, besteht die Aufgabe eines Schiedsgutachters darin, die Beschaffenheit eines Zustandes zu beurteilen; die Pflicht zu einer Leistung steht an sich fest, es sind jedoch ihre Bedingungen sowie ihr Umfang zu klären, siehe ebenda, S. 186. In den hier behandelten Fällen aus dem Jahr 1482 dürfte es sich, wie aus der folgenden Darstellung deutlich wird, um eine Schnittmenge aus beidem handeln.

74 Während z.B. in Quellen und Literatur der Entsatz von Marburg (Maribor) in der Steiermark im Juni 1481 als gelungene militärische Operation Johann Beckensloers und Václav Vlčeks beschrieben wird (s. Unrest, J.: Österreichische Chronik, S. 120f. § 118 und Dopsch, H.: Salzburg, S. 551), warf der kaiserliche Anwalt Vlček und später auch Weispriach vor, nicht gegen die vor der Stadt liegenden ungarischen Truppen gezogen zu sein, siehe auch S. 78-79.

75 Vlček wurden Plünderungen während des Abzuges aus der Steiermark, vor allem bei Graz, Voitsberg, Eibiswald, Wildain und im Mürztal, angelastet. In Niederösterreich wiederum hätten sich seine Truppen, statt Ebergassing und Götzendorf a.d. Leitha zu erobern, bei Bruck a.d. Leitha niedergelassen und die dortigen Untertanen geschädigt.

76 Gwerlich klagte Vlček an, trotz Verlusten in den Truppen den gesamten Sold in Rechnung gestellt zu haben. Dass dieser Soldbetrug jedoch der Hauptkonflikt zwischen dem Kaiser und Vlček gewesen sein soll, wie es Unrest, J.: Österreichische Chronik, S. 121 § 118 darstellt, geht aus dem Verfahrensprotokoll nicht hervor. 
fenstillstandes mit Matthias Corvinus sowie Form- bzw. Verfahrensfehler bei der Absage. ${ }^{77}$ Die Schäden bezifferte der kaiserliche Anwalt auf die immense Summe von 300.000 Gulden, wobei es sich wohl mehr um ein rhetorisches Stilmittel als um eine realistische Schadenforderung handelte.

Der Anwalt Vlčeks blockierte das Schiedsverfahren, indem er eine eingehende Stellungnahme zu diesen Vorwürfen des Kaisers konsequent ablehnte mit der Begründung, seine Vertretungsvollmacht beschränke sich ausschließlich auf die Forderung von Sold und Schadenersatzleistungen. ${ }^{78} \mathrm{Zu}$ den Vorwürfen wolle sich die Bruderschaft erst äuBern, wenn ihnen ihre finanziellen Forderungen sichergestellt würden. Mit diesem Vorgehen machte Schwab mehr als deutlich, was der Feldhauptmann Vlček und die Bruderschaft von diesem vonseiten ihres säumigen Dienstherrn anberaumten Verfahren hielten. Denn die im Verfahrensprotokoll inserierte Vollmacht Vlčeks für Schwab und zwei weitere namentlich genannte Anwälte erlaubte diesen durchaus, umb die spruch die unser herr der kaiser etc. zu mir [Vlček, Anm. P.H.] und meiner bruderschaft vermaint zehaben und umb die scheden die wir genomen haben [...] und auch die besetzung die wir in dem lannd haben von wegen das unns sein kaiserlich gnade unsern trewlichen sold und schaden zu rechter zeit nicht betzallt hat zu verhandeln. Entsprechend lehnten auch die Schiedsrichter die Forderung Schwabs ab, die Klagen des Kaisers Vlček noch einmal schriftlich vorzulegen, um dann mit dessen endgültiger Antwort und einer geänderten Vollmacht wieder vor das Gericht zu treten. Die verfahrene Situation veranlasste den Kaiser schließlich, persönlich vor der Schiedskommission zu erscheinen, um von dieser den vorgesehenen Schiedsspruch einzufordern. Dabei rekurrierte er auf den Schiedsvertrag, in dem explizit festgehalten war, dass am Ende des Verfahrens ein Urteil erfolgen sollte. Die Schiedsrichter erklärten daraufhin einmütig die Fehde Vlčeks für beendet und verlangten von diesem, seine Besatzungen aufzugeben. Den Kaiser wiederum forderten sie auf, die ihm entstandenen Schäden zu belegen, welche den Söldnern gegebenenfalls von deren Forderungen abgezogen werden sollten. Andernfalls sollten die Söldner auf ihre eidliche Aussage hin von den Klagen des Kaisers freigesprochen werden.

Dieses Urteil boykottierten Vlček und seine Bruderschaft jedoch ebenso wie die vorausgegangene Verhandlung. Es scheint, als hätten sie sich noch nicht einmal das Verfahrensprotokoll, das unmissverständlich den Willen des Kaisers dokumentierte, aushändigen lassen. ${ }^{79}$ Vlček dürfte Friedrich III. weiter militärisch unter Druck gesetzt und auf diese Weise seinen im Verlauf des Verfahrens vorgebrachten Vorschlag, die Streitsache in mittler zeit in hanngund(e)n schuben [...] gutlich [zu] vertragen, durchgesetzt haben. Gutlich bedeutete in diesem Fall ganz offensichtlich zu den Bedingungen Vlčeks. Denn ein halbes Jahr nach der Urteilsverkündigung verpflichtete sich Friedrich III. gegenüber dem böhmischen Söldnerführer und dessen Bruderschaft zu einer Zahlung von über

77 Gwerlich klagte, Vlček habe noch vor der offiziellen Eröffnung der Fehde einen Söldnerzug überfallen, der in kaiserlichen Dienst hätte aufgenommen werden sollen, und die später folgende Absage nicht verfahrensgerecht an den üblichen Sitz des Kaisers, sondern nach Eggenburg gesandt.

78 Er verwies lediglich darauf, dass sie den Befehlen Johann Beckensloers gefolgt und zu der Besatzung aufgrund der ausbleibenden Soldzahlungen gezwungen gewesen seien.

79 Die Ausfertigungen für beide Parteien befinden sich nach wie vor im Ausstellerarchiv, vgl. Anm. 1. 
50.000 Pfund Pfennig, die er zum Teil in bar zu leisten versprach und zum Teil auf verschiedene Aufschläge an der Donau sicherstellte. ${ }^{80}$ Dieser Zusage wiederum lag eine schriftliche Vereinbarung der Parteien in Form eines berednuszedels zugrunde. Die Forderungen Friedrichs III. nach Wiedergutmachung waren verhallt. Doch blieben letztlich auch die von Vlček erpressten Zugeständnisse des Kaisers, gleich dem Schiedsverfahren, nicht viel mehr wert als das Pergament, auf dem sie geschrieben waren: Auch im Jahr 1486 hatte Friedrich III. seine verbrieften Schulden gegenüber Vlček noch nicht vollständig beglichen. ${ }^{81}$

Das Verfahren zwischen dem Kaiser und Andreas von Weispriach hingegen versprach, zumindest anfangs, konstruktiver zu verlaufen als das gegen Vlček. Die Parteien verhandelten die relevanten Streitpunkte ausführlich über mehrere Runden Rede und Gegenrede, was vermuten lässt, dass beide eine reale Chance sahen, die Auseinandersetzungen auf diesem rechtlichen Wege für sich entscheiden zu können. Das Verfahren wurde am 14. Januar 1482, dem Tag der Urteilsverkündung im Vlček-Prozess, eröffnet, nachdem der Schiedsvertrag erst zwei Tage zuvor ausgefertigt worden war. In formaler Hinsicht glich das Verfahren weitgehend dem Vlček-Prozess, bis auf einige wenige Änderungen, welche der Hof bzw. die Schiedskommission vorab vornahmen. Dies geschah möglicherweise um zu verhindern, dass Andreas von Weispriach das Verfahren ebenfalls gleich zu Beginn zum Scheitern brachte. Zum einen wurde die Schiedskommission mit dem kaiserlichen Rat Georg Hessler, dem ein besonderes Nahverhältnis zum Kaiser attestiert wird, um einen Obmann verstärkt. ${ }^{82}$ Der Kardinal war nicht nur von Friedrich III. vielfach als Diplomat mit verschiedenen Haus- und Reichsangelegenheiten, zuletzt mit ungarischen Belangen, betraut gewesen. ${ }^{83}$ Er war auch als erst kürzlich vom Kaiser ernannter Bischof von Passau selbst zwischen die Fronten des Ungarnkonfliktes geraten. ${ }^{84}$

Die um diesen Ungarnspezialisten erweiterte Schiedskommission bestimmte nun, dass anders als in dem Prozess gegen Vlček, der ausschließlich mündlich geführt und protokolliert worden war, die ersten Gegenreden der Söldnerpartei schriftlich eingereicht werden sollten. Die schriftliche Vorlage von Klage, Rede und Gegenrede war im Schiedsverfahren durchaus nicht außergewöhnlich, sondern hatte sich bis ins 15 . Jahrhundert vielmehr als eine übliche Vorgehensweise etabliert. ${ }^{85}$ Im Weispriach-Ver-

80 Siehe zwei Urkunden von 1482 August 9 in den REGG.F.III. 35, Nr. 206 und 207; vgl. dazu Schober, K.: Eroberung Niederösterreichs, S. 26-27 und Vancsa, M.: Geschichte Nieder- und Oberösterreichs, S. 512. Die Sicherstellung ausstehender Soldforderungen auf Mauten war ein wiederholt gewählter Ausweg des um Bargeld verlegenen Kaisers, siehe z.B. REGG.F.III. 10, Nr. 471.

81 Siehe CHMEL, Nr. 7825.

$82 \mathrm{Zu}$ Hessler siehe Heinig, P.-J.: Kaiser Friedrich III., S. 709-720, hier vor allem S. 714; vgl. dazu Nehring, K.: Matthias Corvinus, S. 152.

83 Siehe Heinig, P.-J.: Kaiser Friedrich III., S. 714.

84 Hessler konnte sich trotz der Unterstützung kaiserlicher Truppen nicht gegen den Gegenkandidaten des Domkapitels, der ein Bündnis mit Matthias Corvinus geschlossen hatte, durchsetzen, siehe Dopsch, H.: Salzburg, S. 551. Das Schiedsverfahren gegen Weispriach dürfte zu Hesslers letzten wichtigen Einsätzen gezählt haben. Er starb im September 1482. 
fahren entschieden sich die Schiedsrichter dafür, weil sich schon frühzeitig abzeichnete, dass sich die Tatsachen- und Beweisaufnahme komplex gestalten würde und manigerlay rede und widerrede zu erwarten waren. Dies wiederum dürfte darauf zurückzuführen sein, dass ein Teil der Vorwürfe des Kaisers die Gesamtheit der Söldnerführer betraf, während sich einzelne Klagen konkret gegen eine kleinere Gruppe von Rottmeistern richteten. Entsprechend nahm die Schiedskommission von diesen eine eigene schriftliche Stellungnahme entgegen. Andreas von Weispriach wiederum äußerte sich zu den Vorwürfen, welche im Wesentlichen die Gesamtheit der Söldner betrafen.

Die Schiedskommission betrachtete die Schriftlichkeit als Unterstützung des Verfahrens, war sich aber bewusst, dass sie zugleich eine Verlangsamung der Abläufe bedeutete. Deshalb verfügte sie, dass alle weiteren Reden und Gegenreden, und zwar sowohl die des kaiserlichen Anwalts als auch die der Söldner, mündlich erfolgen sollten, um das Verfahren nicht weiter zu behindern. ${ }^{86}$ Die schriftlichen Stellungnahmen der Söldner wurden vor den Schiedsrichtern verlesen, aber auch dem kaiserlichen Anwalt übergeben, was diesem die Gelegenheit geboten haben dürfte, sich sorgfältig auf seine Gegenrede vorzubereiten. Auch eingedenk der Tatsache, dass dem Anwalt der Söldnerpartei im vorangegangen Prozess versagt worden war, die Anklagepunkte des Kaisers Vlček schriftlich vorzulegen, ist zu überlegen, ob nicht möglicherweise im Weispriach-Verfahren mit dieser sorgfältigen Abwägung von Schriftlichkeit und Mündlichkeit dem kaiserlichen Anwalt von Seiten der Schiedskommission bewusst ein Vorteil verschafft werden sollte.

Mit dem offensichtlichen Ziel, den Kaiser von jeglicher finanziellen Verbindlichkeit gegenüber Weispriach und den von diesem vertretenenen Rottmeistern zu entpflichten, verfolgte Wolfgang Gwerlich eine doppelte Strategie. Zum einen stellte er die Recht- und Ordnungsmäßigkeit der vertraglichen und verwaltungstechnischen Grundlagen ihrer Ansprüche auf Sold und Schadenersatzleistungen in Frage. Zum anderen versuchte er, dem Schiedsgericht ein möglichst eindrückliches Bild ihres vermeintlich undisziplinierten, ja unmoralischen Verhaltens während ihres Dienstverhältnisses zu vermitteln. Die von Gwerlich im Namen des Kaisers vor das Schiedsgericht gebrachten Klagen spannten sich von Unregelmäßigkeiten bei der Musterung und eine nicht ausreichende Zahl von Söldnern in den Rotten über Ungehorsam gegenüber kaiserlichen Hauptleuten und Meuterei, Nachlässigkeit bei der Ausführung von Befehlen bzw. Befehlsverweigerung, unrechtmäßige Bereicherung bis zu der zentralen Anklage, in der Steiermark und in Niederösterreich kaiserliche Untertanen ausgeplündert und in den Erblanden ärgere Schäden als die ungarischen Truppen angerichtet zu haben. Gwerlich versuchte, mit seiner Argumentation einen Rechtsbruch auf Seiten der Söldner zu belegen, der die Klagen des Kaisers als Vertragspartner auf Wiedergutmachung legitimierte. Dies war nicht zuletzt deshalb nötig, weil der Einbehalt des zugesagten Soldes sowie der Schadenersatzleistungen durch den Kaiser seinerseits ein Vertragsbruch war, den es vor Gericht plausibel zu rechtfertigen galt. ${ }^{87}$

86 Es folgten noch je zwei weitere Reden bzw. Gegenreden des kaiserlichen Anwalts und der Söldner.

87 „Das wichtigste Merkmal eines Solddienstes, das ihn auch als solchen kennzeichnete“, formuliert Tresp in 
Einer der wichtigsten Bestandteile der vertraglichen Vereinbarungen zwischen Dienstherrn und Söldnern, der damit zugleich die rechtliche Grundlage für die Geltendmachung von Sold und Schadenersatz bildete, war der Schadlosbrief. ${ }^{88}$ Aus dem Verfahrensprotokoll geht hervor, dass Friedrich III. Weispriach im Schadlosbrief die Zahlung von einem Pfund Pfennig pro berrittenem Söldner und einem halben Pfund pro Fußsoldat zugesagt hatte. Dies lag im Rahmen dessen, was der Kaiser Söldnern üblicherweise zu zahlen bereit war. ${ }^{89}$ Es lässt sich nicht eindeutig klären, ob auch die anderen Rottmeister, die für ihre Truppen einen vergleichbaren Sold erhielten, über Weispriachs Schadlosbrief abgerechnet wurden. ${ }^{90}$ Neben dem Sold waren für einzelne militärische Einsätze Zusatz- bzw. Sondervereinbarungen getroffen worden, wie z.B. für einen Zug unter dem sächsischen Hauptmann Sittich von Zedwitz, für den die Soldunternehmer eine Pauschalzahlung von 4.000 Pfund Pfennig für Pferde, Ausrüstung und Waffen zugesagt bekommen hatten, oder für einen vom kaiserlichen Hauptmann Wolframsdorfer angeführten Zug nach Murau in der Steiermark, für den jeder berittene Söldner vier Pfund Pfennig hatte erhalten sollen. Inwiefern diesen Zusatzvereinbarungen ebenfalls schriftliche Verträge zugrunde lagen, wird nicht deutlich.

Die Bezahlung hatte während der Züge über die kaiserlichen Hauptleute abgewickelt werden, also offensichtlich, wie im Söldnergeschäft üblich, in Intervallen erfolgen sollen. ${ }^{91}$ Die Rottmeister klagten dem Schiedsgericht, sie seien von den Hauptleuten ebenso fortwährend vertröstet worden wie von Johann Beckensloer, dessen Räten sowie vom Kaiser selbst. Dieser hatte die Söldner zuletzt über seine Räte und Sittich von Zedwitz mit dem Versprechen, zu einem späteren Zeitpunkt eine erhöhte Prokopfsumme zu bezahlen, sogar um eine Stundung bitten lassen. In dramatischen Bildern beschreiben

diesem Zusammenhang einfach wie treffend, „war der versprochene und gezahlte Sold.“, siehe Tresp, U.: Söldner, S. 269.

88 Siehe ebenda, S. 267-268 sowie Ettelt-Schönewald, B.: Kanzlei, Rat und Regierung, S. 93-94.

89 Im Verhältnis zu der langen Regierungszeit Kaiser Friedrichs III. sind nur wenige von ihm ausgestellte Schadlosbriefe überliefert, was im Hinblick auf ihren Gebrauchscharakter nicht weiter verwundert, siehe ein Konvolut Schadlosbriefe von 1455/56 für einen Feldzug gegen die Türken in REGG.F.III. 32, Nr. 79-82, 85-101, 104-112; siehe des Weiteren Regesten Kaiser Friedrichs III. (1440-1493). Nach Archiven und Bibliotheken geordnet. Heft 22. Die Urkunden und Briefe des Österreichischen Staatsarchivs in Wien, Abt. Haus-, Hof- und Staatsarchiv: Allgemeine Urkundenreihe, Familienurkunden und Abschriftensammlungen (1464-1469). Bearb. von Christine Ottner (= REGG.F.III. 22), Nr. 279; Regesten Kaiser Friedrichs III. (1440-1493). Nach Archiven und Bibliotheken geordnet. Heft 27. Die Urkunden und Briefe des Österreichischen Staatsarchivs in Wien, Abt. Haus-, Hof- und Staatsarchiv: Allgemeine Urkundenreihe, Familienurkunden und Abschriftensammlungen (1470-1475). Bearb. von Sonja Dünnebeil und Daniel Luger. Wien u.a. 2012 (= REGG.F.III. 27), Nr. 8 sowie für die Zeit von 1480 bis 1486 Regesten Kaiser Friedrichs III. (1440-1493). Nach Archiven und Bibliotheken geordnet. Heft 10. Die Urkunden und Briefe aus den Archiven und Bibliotheken des Landes Thüringen. Bearb. von Eberhard Holtz, Wien u.a. 1996 (= REGG.F.III.10), Nr. 472; REGG.F.III. 35, Nr. 64 und 209; Regesten Kaiser Friedrichs III. (1440-1493). Nach Archiven und Bibliotheken geordnet. Heft 30. Die Urkunden und Briefe des Österreichischen Staatsarchivs in Wien, Abt. Haus-, Hof- und Staatsarchiv: Allgemeine Urkundenreihe, Familienurkunden und Abschriftensammlungen (1483-1488). Bearb. von Peter Gretzel. Wien u.a. 2014 (= REGG. F.III. 30), Nr. 131 und 194 sowie CHMEL, Nr. 7387 und 7499.

90 Vgl. dazu S. 65 Anm. 34.

91 Siehe Tresp, U.: Söldner, S. 271. 
die Rottmeister, wie das vergebliche Warten auf das Geld sowie auf weitere Befehle des Kaisers die Söldner an die Grenze ihres physischen und psychischen Vermögens gebracht habe. ${ }^{92}$

Möglicherweise hatte Weispriach nach seiner einseitigen Aufkündigung des Dienstverhältnisses vom Kaiser bereits eine konkrete Geldsumme verlangt. Gwerlich jedenfalls deklarierte die Forderungen Weispriachs als unrechtmäßig mit der Begründung, der Schadlosbrief laute nicht allein auf diesen, sondern auch auf Leonhard Kollnitzer. Die Ausstellung des Schadlosbriefes auf mehrere Rottmeister war eigentlich nicht außergewöhnlich, ${ }^{93}$ wobei allerdings eine korrekte Angabe der Begünstigten durchaus relevant war, da ein Dienstherr Geld in der Regel nicht an Dritte auszahlte. ${ }^{94}$ Der Verdacht, den Gwerlich aber wohl an dieser Stelle mit dem Hinweis auf die Doppelausstellung des Schadlosbriefes schüren wollte, ${ }^{95}$ war der, dass Weispriach zu hohe Forderungen stellte, zumal seine Sold- und Schadenersatzforderungen mit den von ihm während der Kriegszüge eingenommen Geleit- und Huldigungsgeldern zu verrechnen waren, was die Gesamtsumme noch einmal reduziert hätte. ${ }^{96}$ Nach Weispriachs Einwand, er habe dem Kaiser diesbezüglich ohnehin noch eine Abrechnung vorlegen wollen, weshalb die Einlassungen Gwerlichs völlig überflüssig seien, brach dieser die Diskussion um den Schadlosbrief abrupt ab mit dem Argument, es gehe in dem Verfahren ohnehin nicht um die Bezahlung der Söldner, sondern um die Entschädigung des Kaisers.

Dieses Argument erklärt allerdings nur vordergründig, weshalb die Behandlung des Schadlosbriefes im Hinblick auf das gesamte Schiedsverfahren überraschend randständig erscheint. ${ }^{97}$ Der Grund dafür dürfte vielmehr darin zu suchen sein, dass sich dem kaiserlichen Anwalt weniger bei den vertraglichen Bedingungen des Dienstverhältnisses als mehr bei den verwaltungstechnischen Bemessungsgrundlagen der Sold- und Schadenersatzansprüche eine Angriffsfläche bot, um die Rechtmäßigkeit von Weispriachs Forderungen in Frage zu stellen. Gwerlich tat dies, indem er den Rottmeistern Unregelmäßigkeiten bei der Musterung unterstellte. Während der Schadlosbrief die Ansprüche der Söldner rechtlich begründete, lieferten die schriftliche Musterung der Söldner samt Pferden und Ausrüstung sowie das „verwaltungstechnische Gegenstück“ der Musterung, die Schadenrechnung, die nötigen Daten zur Festsetzung der vom Dienstherrn zu leistenden

92 Anscheinend hatten diese von ihrem Sold auch ihre Verpflegung zu bestreiten, weshalb sie aufgrund der ausbleibenden Zahlungen Not und Hunger litten; zu den Vereinbarungen bezüglich der Versorgung der Truppen siehe ebenda, S. 289-293.

93 Siehe z.B. REGG.F.III. 10, Nr. 472.

94 Siehe Tresp, U.: Söldner, S. 271; vgl. dazu eine im Jahr 1486 von Friedrich III. ausgestellte Urkunde, aus der hervorgeht, dass der Kaiser den letztgültigen Schadlosbrief erst in Kenntnis der Namen der Rottmeister ausstellen wollte, siehe REGG.F.III. 30, Nr. 227.

95 Die Vorgänge lassen sich aus den jeweiligen Reden und Gegenreden nur lückenhaft rekonstruieren.

96 Zur Verrechnung von Sonderzahlungen siehe Tresp, U.: Söldner, S. 283-289.

97 Er wurde erst gegen Ende des Schiedsverfahrens überhaupt thematisiert, wobei es in Schiedsverfahren durchaus üblich war, dass Parteien auch in späteren Gegenreden noch „neues Tatsachenmaterial“ in einen Prozess einbrachten, siehe Bader, K. S.: Schiedsverfahren, S. 201. 
Zahlungen. ${ }^{98}$ Die hier entscheidende Größe war der Schadenersatz, da dieser einen erheblichen Anteil der Gesamtkosten eines Söldnerheeres ausmachte und, anders als die vereinbarten Soldzahlungen, für die Vertragsparteien ein großes finanzielles Risiko barg, da die Höhe möglicher materieller Verluste bei Dienstantritt nur schwer kalkulierbar war. ${ }^{99}$ Für den Dienstherrn wiederum war der Einbehalt von Schadenersatzleistungen ein probates Mittel, um undiszipliniertes Verhalten der Truppen zu sanktionieren. ${ }^{100}$

Die Truppen der von den Vorwürfen betroffenen Rottmeister waren 1481 in Wien gemustert worden. Danach waren bei einem Zug in die Steiermark viele der Söldner dem kaiserlichen Anwalt zufolge mehr als einhundert - gestorben. Gwerlich behauptete, die Rottmeister hätten diese ohne Kenntnis der zuständigen kaiserlichen Hauptleute, welchen die Abnahme der ordnungsgemäßen Musterung oblag, ${ }^{101}$ durch andere ersetzt. Damit unterstellte Gwerlich den Rottmeistern nicht nur einen formalen Fehler, sondern zielte offensichtlich auch darauf ab, dass sie nicht genügend Dienstleute in ihren Rotten gehabt hatten. Dieser Vorwurf wird zwar an dieser Stelle im Protokoll nicht explizit formuliert, aber im Schiedsurteil als einer der zentralen Klagepunkte des Kaisers noch einmal aufgegriffen. Die Rottmeister behaupteten ihrerseits, Name und Todeszeitpunkt eines jeden verstorbenen Söldners sehr wohl mit Wissen der Hauptleute exakt notiert zu haben, also gleichsam die Musterungslisten während der Züge fortwährend aktualisiert zu haben. Als Beweis führten sie einen Brief des kaiserlichen Hauptmanns Wolframsdorfer an, in dem dieser angeblich dem Kaiser bestätigt hatte, dass die Truppen zu Wien ordnungsgemäß gemustert worden und vollzählig gewesen waren. Dies würde zudem, so die Rottmeister, aus der Abrechnung des Hubschreibers hervorgehen, der ebenfalls der Musterung beigewohnt habe.

Bei dieser raittung des Hubschreibers dürfte es sich um eine abschließende Schadenrechnung bei Dienstende handeln. Bei den Truppen Weispriachs waren offensichtlich bereits während des Solddienstes in Intervallen schriftliche Schadenerhebungen vorgenommen worden, denn Weispriach forderte in seiner Eingangsklage vom Kaiser Geld für die sider der raittung am jungsten mit in beschehen entstandenen Verluste. Geldzahlungen von Seiten des Kaisers waren mit diesen zurückliegenden Abrechnungen jedoch offensichtlich keine verbunden gewesen. ${ }^{102}$ Gwerlich jedenfalls wies die Existenz einer (abschließenden) Abrechnung des Hubschreibers Mert Burger konsequent zurück, da des v(er)mainten aufnemen von der kaiserlichen maiestat hawbtlewten khain auffschreiben noch musster beschehen wie hab man dann ainigerlay raittung hie mit in mugen besliessen. Der neben Gwerlich als kaiserlicher Anwalt am Verfahren teilnehmende Burger äußerte sich nicht erkennbar dazu. Schließlich zweifelte Gwerlich auch die Existenz des Briefes Wol-

98 Zur Musterung siehe Tresp, U.: Söldner, S. 331-341; zur Schadenrechnung siehe ebenda, S. 341-351, das Zitat siehe S. 341.

99 Zur spätmittelalterlichen Schadenersatzpraxis, einem „Rechtsbereich eigener Prägung, der eine besondere Verwaltungstätigkeit hervorrief“, siehe ebenda, S. 318-361, hier vor allem S. 322-324 sowie S. 327.

100 Siehe ebenda, S. 327.

101 Vgl. dazu ebenda, S. 333-334.

102 In seinem Schlussplädoyer sagte Weispriach, der Kaiser habe ihm und den anderen Rottmeistern zu keinem Zeitpunkt Schadenersatz bezahlt, obwohl sie ihm weitaus länger als Václav Vlček gedient hätten. 
framsdorfers mit dem naheliegenden Argument an, hätte dieser tatsächlich dem Kaiser geschrieben, dürfte sich der Brief nicht mehr in den Händen der Söldner befinden. Selbst wenn ein solcher existierte, war Gwerlich nicht bereit, ihn als Beweismittel zu akzeptieren. Entscheidend für ihn blieb, dass aufgrund der fehlenden Abnahme durch die kaiserlichen Hauptleute die Musterung unautorisiert blieb und damit keine ordnungsgemäße, gültige Grundlage für die Sold- und Schadenersatzforderungen der Söldner darstellte.

Alle weiteren während des Schiedsverfahrens vom Kaiser gegen die Söldner vorgebrachten Klagen lassen sich unter den Schlagworten ungehorsam, lessigkait, versawmnuss und unbillich hanndlung subsumieren. Weispriach und die von ihm vertretenen Rottmeister befanden sich angesichts der Schwere der Vorwürfe von Beginn des Verfahrens an in der Defensive. Sie waren deshalb sehr viel stärker als der kaiserliche Anwalt darum bemüht, ihre Verteidigung plausibel zu begründen. Dabei setzten sie gleich diesem auf eine stark emotionalisierte Schilderung der Ereignisse, untermauerten diese aber zusätzlich an geeigneten Stellen mit Hinweisen auf Schriftstücke, die ihr Handeln begründen bzw. legitimieren sollten. So verwiesen die Söldner z.B., abgesehen von den Schadlosbriefen, Musterungslisten und Schadenrechungen, die vor allem Anfang und Ende des Soldgeschäftes flankierten, zur Legitimierung ihrer finanziellen Ansprüche auf Verwaltungsschriftgut, das originär im Feld produziert worden war.

Wolfgang Gwerlich warf den Söldnern vor, in der Steiermark gegen den kaiserlichen Hauptmann Jörg Wolframsdorfer gemeutert und im Zuge dessen die Lade mit dem Brandschatzungs- und Huldigungsgeld an sich gebracht zu haben. ${ }^{103}$ Diese Gelder waren offensichtlich bei Eingang von einem vereidigten kaiserlichen Schreiber verzeichnet worden und hatten sich in der Obhut des Hauptmanns befunden. Die Rottmeister behaupteten nun vor Gericht, Wolframsdorfer habe ihnen nicht nur versprochen, ihnen von diesem Geld ihren Sold sowie Schadenersatz zu zahlen, sondern sei sogar vom Kaiser schriftlich angewiesen worden, den Söldnern pro Kopf eine bestimmte Summe auszuzahlen. Da der Hauptmann jedoch sein Wort gebrochen und sie bezüglich der Summe der vorhandenen Gelder belogen hatte, hatten sie anscheinend, um sich Klarheit zu verschaffen, den kaiserlichen Schreiber gefangengesetzt. ${ }^{104}$ Den ihnen als Meuterei zur Last gelegten Aufruhr schilderten die Rottmeister als eine Art Versehen: Sie hätten zum Angriff blasen lassen, weil sie die Feinde in der Nähe wähnten. Der vereidigte Schreiber wiederum unterstützte die Söldner nun vor dem Schiedsgericht, weil er seinerseits vom Kaiser noch nicht entlohnt worden war, und bot an, ein geschrift oder registere der hanndlung mit der huldigung vorzulegen. Während Gwerlich in seiner Gegenargumentation dieses Register als Beweismittel gänzlich ignorierte, weil er es wahrscheinlich als solches für ungefährlich hielt, erklärte er den Brief des Kaisers an den Hauptmann, mit dem die Rottmeister ihre Ansprüche auf die Huldigungsgelder begründeten, ausdrücklich als wirkungslos, da sie die besagte Lade gewaltsam und damit unrechtmäßig an sich gebracht hätten.

103 Ein Beispiel für eine Meuterei zur Zeit der Soester Fehde bietet Tresp, U.: Söldner, S. 275-276.

104 Die Zusammenhänge lassen sich an dieser Stelle nur schwer rekonstruieren. 
Ferner machte Gwerlich im Namen Friedrichs III. Weispriach und die von ihm vertretenen Rottmeister in einem wiederkehrenden Muster für unzufriedenstellend verlaufene militärische Operationen mitverantwortlich, von denen den Kaiser einige, wie der erneute Durchzug ungarischer Truppen durch die Steiermark, empfindlich getroffen haben dürften. ${ }^{105}$ Diesen neuerlichen Einfall der Ungarn legte der Kaiser Andreas von Weispriach zur Last, der mit seinen Truppen ohne Befehl aus dem Land abgezogen sei.

Weispriach und die Rottmeister wiederum schoben die Verantwortung für die ihnen angelasteten Fehlleistungen konsequent auf übergeordnete Stellen. Zur Untermauerung ihrer Argumentation verwiesen sie auf verschiedene Schriftstücke, die ihr Handeln erklären bzw. legitimieren sollten. Dazu zählten schriftliche Nachrichten zwischen den Söldnerführern, (Marsch-)Befehle übergeordneter Stellen, Friedens- bzw. Waffenstillstandsverträge sowie so genannte einlassbriefe. Der Urkundenbeweis hatte im Schiedsverfahren im Vergleich zu anderen Formen der Beweisführung ab dem 14. Jahrhundert zunehmend an Bedeutung gewonnen, ${ }^{106}$ das Vorgehen der Söldner war also durchaus üblich. Allerdings fällt auf, dass die Weispriach-Partei dem Schiedsgericht die betreffenden Schriftstücke nur in sehr wenigen Fällen auch physisch vorlegte, was daran gelegen haben dürfte, dass Gebrauchsschrifttum wie Marschbefehle, welche die Söldner überwiegend von Johann Beckensloer bzw. vom Kaiser selbst erhalten hatten, zum Zeitpunkt des Schiedsverfahrens bereits nicht mehr vorhanden war. ${ }^{107}$ Gegen den Vorwurf, sie seien unerlaubt von dem steirischen Murau abgezogen, konnten die Rottmeister jedoch sogar einen Befehl des Kaisers selbst vorlegen, mit dem dieser sie von Murau nach Graz abkommandiert hatte.

Ferner beklagte der Kaiser ein mangelndes Engagement der Söldner beim Entsatz von Marburg. Nun war es Gwerlich, der die Schiedsrichter darauf hinwies, dass die Söldner gleich mehrmals vom Kaiser schriftlich dazu aufgefordert worden seien, gegen die vor der Stadt liegenden ungarischen Truppen zu ziehen. ${ }^{108}$ Während sich Weispriach auf die Position eines Befehlsempfängers zurückzog und sich damit entschuldigte, sie hätten mit ihren Truppen Beckensloer und Vlček unterstanden, gaben andere Rottmeister in ihren Gegenreden an, die kaiserlichen Hauptleute in Graz hätten sie zwar Richtung Wildhaus (Viltuš) bei Marburg abkommandiert, dann aber sei ein fridbrief ${ }^{109}$ des Kaisers

105 Im Februar 1480 waren schon einmal ungarische Truppen in die Steiermark und in Kärnten eingefallen, nachdem Matthias Corvinus vom Kaiser unter dem Vorwand, gegen die Türken und Venezianer kämpfen zu wollen, vergeblich den Durchzug seiner Truppen durch die Erblande gefordert hatte, siehe Dopsch, H.: Salzburg, S. 549 .

106 Siehe Bader, K. S.: Schiedsverfahren, S. 203-204, der als weitere gängige Beweismittel in Schiedsverfahren neben dem Urkundenbeweis den Parteieneid und die Zeugenaussage nennt.

107 Es wird zudem nur für einen Teil der im Verfahrensprotokoll genannten Marschbefehle ausdrücklich erwähnt, dass sie schriftlich erfolgt waren.

108 Gwerlich machte Weispriach sogar für die bei Marburg durch Václav Vlček entstandenen Schäden verantwortlich, da der Kaiser diesen aufgrund der Befehlsverweigerung Weispriachs dorthin habe entsenden müssen.

109 Möglicherweise handelte es sich um den im Mai 1481 zwischen dem Kaiser und Matthias Corvinus ver- 
eingetroffen, weshalb der Zug wieder kehrtgemacht habe. ${ }^{110}$ Hinsichtlich der Truppensteuerung hatten demnach Waffenstillstandsverträge im Feld eine den Marschbefehlen vergleichbare operative Funktion, auch wenn sie in diplomatischer Hinsicht von diesen zu unterscheiden sind.

Doch auch Schreiben von Ausstellern weniger hoher Autorität vermochten die Söldner in Bewegung zu setzen. So rechtfertigen sich die Rottmeister gegen den Vorwurf, sie hätten steirische und Kärntner Landleute nicht im Kampf um Neumarkt unterstützt, damit, dass sie lange Zeit überhaupt nicht um Hilfe gebeten worden seien. Als sie jedoch eines Sonntagsmorgens in der Kirche gewesen seien, habe sie ein Schreiben von Leonhard Kollnitzer erreicht, dass die Feinde mit 3.500 Mann auf das Heerlager zögen, woraufhin sie unverzüglich reagiert hätten.

Mit dem Hinweis auf einen weiteren Friedbrief des Kaisers verfolgten die Söldner aber offensichtlich ein anderes Ziel als das der Legitimation ihres Handelns. Der Graf von Görz hatte ihnen die Abschrift einer verschreibung ains fridhalben übermittelt, mit der Friedrich III. anscheinend die Schonung salzburgischer Herrschaften und Täler in der Steiermark garantiert hatte. ${ }^{111}$ Weispriach betonte, dass sie sich nicht angemaßt hätten, in der kaiserlichen maiestat brief und sigl einzugreifen. Sicher nicht zufällig hatten sie unmittelbar zuvor darauf hingewiesen, zwei der Rottmeister hätten in einem von Beckensloer im Namen des Kaisers ausgestellten Brief die Erlaubnis erhalten, im Lungau Huldigungsgelder einzunehmen, und seien in einem weiteren Schreiben versichert worden, das Geld behalten zu dürfen. Offensichtlich versuchten sie der Schiedskommission zu vermitteln, dass sie die Briefe des Kaisers für sich als bindend betrachteten so wie dies umgekehrt auch vom Aussteller einforderten.

Der letztlich schwerwiegendste Vorwurf des Kaisers gegenüber den Söldnern war der, in der Steiermark und in Niederösterreich seine Untertanen ausgeplündert zu haben. Entsprechend breiten Raum nahm die Diskussion um diesen Punkt im Verlauf des Verfahrens ein. Im Hinblick auf die Schriftlichkeit rücken in diesem Zusammenhang die so genannten einlassbriefe in den Fokus, deren Wirkungslosigkeit aus Perspektive der Söldner wesentlich zu den im Folgenden beschriebenen Vorkommnissen in den Erblanden beigetragen hatte.

Die Söldnertruppen um Weispriach seien, so klagte der kaiserliche Anwalt an, nicht wie befohlen von Ungarn in den salzburgischen Lungau gezogen, sondern hätten sich um Judenburg, Leoben, Voitsberg, Knittelfeld und andere steirische Orte gelagert und dort die Landleute geschädigt, und zwar schlimmer, so Gwerlich, als es die Feinde getan hätten. Nach ihrem Abzug aus der Steiermark und ihrem Feldzug gegen die Ungarn

einbarten Waffenstillstand, der nach mehrfacher Verlängerung schließlich Mitte Juni des Jahres endete, siehe Nehring, K.: Matthias Corvinus, S. 139.

110 Diese Begebenheit legt zudem nahe, dass sich nicht alle der im Verfahren von Weispriach vertretenen Rottmeister mit ihren Truppen zu jeder Zeit am gleichen Ort befunden hatten.

111 Zur Behandlung der salzburgischen Untertanen und Besitzungen im Jahr 1481 siehe Dopsch, H.: Salzburg, S. 551-554. 
unter Sittich von Zedwitz waren die Truppen dann in Niederösterreich zunächt nach Laxenburg südlich von Wien und von dort weiter in Richtung Norden nach Döbling, Kahlenberg, Grinzing, Sievering, Nussdorf und schließlich bis auf das Tullnerfeld gezogen. Die Söldner, so Gwerlich, hätten den Bewohnern den Wein ausgetrunken, Kleidung, Pferde und Wagen abgenommen, die Mühlen bei Tulln ausgeraubt, Frauen Gewalt angetan sowie Gotteshäuser und Friedhöfe geschändet. In seinem Ansinnen die Truppen Weispriachs moralisch zu diskreditieren, warf der kaiserliche Anwalt ihnen also eine breite Palette von im spätmittelalterlichen Krieg sanktioniertem Verhalten vor. ${ }^{112}$

Es steht außer Frage, dass die Truppen marodierend durch die kaiserlichen Erblande gezogen waren, nicht zuletzt weil es Andreas von Weispriach in seinem Schlussplädoyer selbst zugab. ${ }^{113}$ In seinen Augen handelte es sich jedoch um bei Kriegszügen unvermeidbare Kollateralschäden, zumal seine Truppen weder Geld bekommen hätten noch in die Städte eingelassen worden seien, um sich zu versorgen. ${ }^{114}$ Die Rottmeister stritten aber das ihnen vorgeworfene Ausmaß der Verheerungen ab. Armuthalben hätten sie zugegriffen, maßvoll und im Rahmen eines üblichen Lebensunterhaltes. Gwerlich hielt dagegen, von einem einzelnen Mann 32 Mut Hafer, Heu im Wert von 24 Pfund Pfennig sowie einen Dreiling und zwei halbe Fuder Wein im Wert von über 160 Pfund Pfennig zu nehmen, sei kein übliches Maß. Dieses Beispiel war ein deutliches Signal des kaiserlichen Anwalts sowohl an die Söldner als auch an die Schiedsrichter, dass auch alle weiteren durch die Söldner entstandenen Schäden nötigenfalls schriftlich oder mündlich belegt werden könnten.

$\mathrm{Zu}$ ihrer Verteidigung führten die Söldner wiederholt die Wirkungslosigkeit der einlassbriefe ins Feld, die ihnen Zugang zu den landesfürstlichen Städten hätten verschaffen sollen. Solche Briefe hatten sie von Johann Beckensloer bzw. vom Kaiser für Knittelfeld, Judenburg, Leoben, Bruck a.d. Mur, Rottenmann, Schladming und Graz in der Steiermark sowie für das niederösterreichische Tulln erhalten. Beckensloer hatte in dem Einlassbrief für Judenburg der Stadt im Gegenzug für die Aufnahme der Söldner eine schriftliche Garantie gegeben, für eventuelle Verluste finanziell aufzukommen. Doch solche schriftlichen Versprechen hatten auf die steirischen Städte offensichtlich weit weniger Eindruck gemacht als die Horden ausgezehrter Söldner vor ihren Stadttoren. Mit puchs(e)n und armbst an die mewler hätten die Bewohner von Leoben sie empfangen, schilderten die Söldner dem Schiedsgericht. Vor Tulln hatten sich den Schilderungen Weispriachs zufolge dramatische Szenen abgespielt: Trotz der nahenden Feinde und der Vorlage eines kaiserlichen Einlassbriefes hätte der kaiserliche Hauptmann Wolframsdorfer den Truppen den Zugang zur Stadt verwehrt. Der Führer der ungarischen Truppen

112 Autorisierte Beutezüge waren von Seiten eines Kriegsherrn nicht unbedingt unerwünscht, und auch Friedrich III. traf mit Söldnern Vereinbarungen, dass sie sich an feindlichem Gut schadlos halten sollten. Leib und Gut der Untertanen eines Kriegsherrn jedoch sowie dessen Städte und Kirchen standen üblicherweise unter besonderem Schutz, siehe Tresp, U.: Söldner, S. 293-297 sowie REGG.F.III. 30, Nr. 194 und Nr. 131.

113 Auch der Chronist Unrest berichtet davon, siehe Unrest, J.: Österreichische Chronik, S. 120 § 117.

114 Notleidende, marodierende Söldnertruppen waren in Österreich und den Nachbarländern kein ungewöhnliches Bild, siehe Vancsa, M.: Geschichte Nieder- und Oberösterreichs, S. 475-476 und 499. 
Johann Zelený sei von Ungarn über Eisenstadt bis an den Neusiedler See gezogen und habe die kaiserlichen Truppen mit Abstand von vier Stunden über Traiskirchen bis auf das Tullnerfeld vor sich hergetrieben. Diese hätten Wolframsdorfer vergeblich um Einlass nach Tulln gebeten. Erst als die Feinde sie bereits auf den Stadtgraben drängten, habe dieser wenigstens die Wagenburg eingelassen, später in der Nacht dann einen Teil der Truppen in den Hundezwinger, der Rest aber habe auf dem Feld bleiben müssen. Die zunehmend bedrückende Lage habe die Söldner schließlich dazu bewogen, über die Donau zu ziehen und in letzter Konsequenz ihren Dienst zu quittieren.

Das Urteil, das die Schiedsrichter unter dem Vorsitz Georg Hesslers im Verfahren zwischen Kaiser Friedrich III. und Andreas von Weispriach fällten, fiel im Hinblick auf die Länge und Intensität der Beweisaufnahme kurz aus. Die Schiedsrichter attestierten den Rottmeistern, sie hätten billich beigebracht, durchgehend die gesamte Anzahl Söldner in ihren Rotten gehabt und die verstorbenen Dienstleute auf Befehl der kaiserlichen Hauptleute ersetzt zu haben. Den Kaiser wiederum forderten sie ähnlich wie im VlčekVerfahren auf, ungehorsam und saumnuss der Söldner zu belegen und für die Schäden, welche diese seinen Landleuten zugefügt haben sollen, Beweise vorzulegen. Binnen einer genannten Frist sollte eine redliche rayttung stattfinden, im Rahmen derer diese Schäden gegebenenfalls von den Sold- und Schadenersatzforderungen der Söldner abgezogen werden sollten.

Friedrich III. kam der Aufforderung der Schiedsrichter nach und verlangte von den Städten, die Weispriach belagert hatte, schriftliche Auskünfte über die von dessen Truppen verursachten Schäden. ${ }^{115}$ Der Chronist Unrest zeigte Verständnis für die Forderung des Kaisers auf Wiedergutmachung als sein Recht als Landesherr, doch nicht ohne zu bemerken, wiewohl den lewdten, den ir guet genomen was, wenig damit geholfen was. ${ }^{116}$

Das Schiedsurteil erscheint auf den ersten Blick ausgewogen, doch das gesamte Schiedsverfahren war es nicht. Andreas von Weispriach jedenfalls sah nach dem Ende des Verfahrens im Januar 1482 keine Chance mehr auf einen konstruktiven Ausgang des Konfliktes mit dem Kaiser. Er zog die Konsequenzen und lief mit seinen Truppen zu Matthias Corvinus über. Dieser machte Weispriach zu einem seiner Hauptleute, die nach der neuerlichen Kriegserklärung des Königs an den Kaiser noch im selben Jahr das ungarische Heer gegen Friedrich III. anführten. ${ }^{117} \mathrm{Zu}$ der im Schiedsurteil angekündigten rayttung kam es nicht mehr, doch den Söldnern als den Adressaten des Verfahrensprotokolls dürfte klar gewesen sein, dass es einer weiteren Abrechnung nicht mehr bedurfte. Das Schiedsverfahren war bereits die „Abrechnung“ des Kaisers mit den widersätzigen Söldnern und das Protokoll die schriftliche Dokumentation. ${ }^{118}$

115 Siehe Unrest, J.: Österreichische Chronik, S. $120 \S 117$.

116 Siehe ebenda, S. $120 \S 117$.

117 Siehe Unrest, J.: Österreichische Chronik, S. $120 \S 117$ sowie Hoensch, J. K.: Matthias Corvinus, S. 184.

118 Diese Interpretation der Protokolle steht in einem gewissen Widerspruch zu der Sichtweise z.B. Michael Juckers, der Protokolle politischer Sitzungen untersucht und herausstellt, dass Schriftlichkeit in Protokollform den Vorteil habe, Konflikte zu kanalisieren und damit zu entschärfen, siehe Michael Jucker: Pragmatische Schriftlichkeit und Macht: Methodische und inhaltliche Annäherungen an Herstellung und 
Am Ende der langen Beweisaufnahme forderte Andreas von Weispriach schließlich, ihn und die anderen Rottmeister unverzüglich abzufertigen und ihnen nicht wort fur gellt zu geben. Damit dürfte der Kärntner Soldunternehmer die Absicht hinter den beiden vom kaiserlichen Hof initiierten Schiedsverfahren vom Januar 1482 im Kern getroffen haben. Sie waren sowohl eine verbale Hinhaltetaktik eines kaiserlichen Dienstherrn, der kein Geld hatte, um die von ihm angeworbenen Truppen vertragsgemäß zu bezahlen. Zugleich waren sie eine, letztlich wirkungslose, Machtdemonstration eines brüskierten Kaisers, der über keine militärischen Mittel verfügte, um seine Autorität als Kriegs- und Landesherr gegenüber Söldnern durchzusetzen, die seine Untertanen ausgeplündert, Befehle verweigert, ihn befehdet und das Dienstverhältnis einseitig aufgekündigt hatten.

Worte und mit ihnen Schriftlichkeit gehörten zum elementaren Herrschaftsinstrumentarium Friedrichs III., der aufgrund seiner extensiven Urkundenproduktion als „schriftlich regierende[r] Kaiser" gilt. ${ }^{119}$ Im Fall der Schiedsverfahren, an denen er als Partei teilnahm, konnte er selbst nicht als Aussteller fungieren. Dies übernahm gleichsam stellvertretend die Schiedskommission, welche die beiden Verfahren in seinem Interesse geführt hatte. Dass Richter, wie hier, parteiisch im Sinne des Kaisers agierten, war keine Ausnahmeerscheinung. Vielmehr gilt die Instrumentalisierung von Gerichtsbarkeit zur Durchsetzung kaiserlicher Politik unter Friedrich III. eher als Regel denn als Ausnahme. ${ }^{120}$

Im Zuge der Konfliktbewältigung zwischen Friedrich III. und den Söldnerführern entfaltete Schriftlichkeit ihre Wirkung jedoch nicht erst am Ende der Verhandlungen in Gestalt der Verfahrensprotokolle. Schriftlichkeit eröffnete wie beschränkte bereits im Vorfeld sowie während der Schiedsverfahren verschiedene Handlungsspielräume.

Zum einen gab Schriftlichkeit den Schiedsverfahren einen relativ festen Rahmen vor, in dem sich die Parteien zu bewegen hatten. Es mussten Schiedsverträge ausgefertigt, Vollmachten für die Parteienanwälte ausgestellt und je nach Vorgabe der Schiedsrichter schriftliche Reden und Gegenreden ausgearbeitet werden. Dies erforderte Zeit, Präzision und juristische Kenntnisse. Zwar konnte Schriftlichkeit, wie durch die Forderung nach schriftlicher Vorlage der Reden, die Prozessabläufe verlangsamen, sie vermochte damit aber zugleich, komplexe Zusammenhänge sinnvoll zu strukturieren. Zugleich war die den Schiedsverfahren eigene Schriftlichkeit flexibel genug, um gewisse Anpassungsleistungen zugunsten von Parteien vorzunehmen, wie z.B. bei der Gestaltung der Schiedsverträge, die es dem Kaiser ermöglichte, an einem von seinen Untertanen ge-

Gebrauch von Protokollen auf politischen Treffen im Spätmittelalter. In: Zwischen Pragmatik und Performanz: Dimensionen mittelalterlicher Schriftkultur. Hg. von C. Dartmann. Thomas Scharff und Christoph Friedrich Weber. Darmstadt 2011, S. 405-441, hier S. 439.

119 Siehe Eibl, Elfie-Marita: Der schriftlich regierende Kaiser. Kanzlei und Urkundenproduktion zur Zeit Kaiser Friedrichs III. (1440-1493). In: Belliculum diplomaticum II Thorunense. Kancelarie władców na ziemiach polskich w średniowieczu i czasach nowożytnych na tle porównawczym. Hg. von W. Chorążyczewski und J. Tandecki, Toruń 2007, S. 11-22.

120 Siehe Reinle, Christine: Zur Gerichtspraxis Kaiser Friedrichs III. In: Kaiser Friedrich III. (1440-1493) in seiner Zeit. Hg. von P.J. Heinig. Beihefte zu J. F. Böhmer, Regesta Imperii 12. Köln u.a. 1993, S. 317-353, hier S. 352. 
leiteten Verfahren teilzunehmen, ohne seine Stellung als Reichsoberhaupt und oberster Richter zu kompromittieren.

Schriftlichkeit fungierte vor allem aber auch als belastbares Element einer plausiblen Beweisführung der Parteien sowie zur Legitimation strittigen Handelns, das es den Schiedsrichtern nachvollziehbar zu erklären galt. Eine besondere Bedeutung kam in diesem Zusammenhang dem pragmatischen Schriftgut zu, das im Rahmen des Dienstverhältnisses zwischen Kriegsherrn und Söldnern entstanden war. Da Schadlosbrief, Musterungslisten und Schadenrechnung die zu erbringenden Vertragsleistungen nachprüfbar machten, boten sie den Vertragsparteien im Konfliktfall eine Absicherung. Selbst eine Schiedskommission, die im Interesse einer Partei agierte, vermochte sie nicht gänzlich zu ignorieren. Deshalb war es ein Ziel der Parteienanwälte, die Qualität bzw. Mangelhaftigkeit dieses Schriftgutes zu belegen. Dieses diente damit also nicht allein als Beweismittel, sondern wurde selbst zum Gegenstand der Verhandlungen.

Als Legitimationsmittel war zudem vor allem solches Schriftgut geeignet, das im Hinblick auf den Aussteller eine besondere Autorität versprach. Das konnten z.B. Briefe oder Befehle der Feldhauptleute, vor allem aber des Kaisers selbst sein. Ein Nachteil solcher Schriftstücke konnte lediglich darin bestehen, dass sie aufgrund ihres Gebrauchscharakters nicht mehr physisch vorhanden waren. Ihr ursprünglicher Zweck zielte nicht auf einen potentiellen Konfliktfall ab, sondern lag vielmehr im Alltagsgeschäft des Krieges begründet, wie z.B. in der Übermittlung von Befehlen oder Nachrichten. Konflikte entstanden zudem da, wo sich Schriftgut dem Zugriff einer Partei entzog, wie an den Diskussionen um das Huldigungsregister zu sehen war.

Die Wirksamkeit von Schriftlichkeit ergab sich letztlich aus der Bedeutung, die ihr von den Streitparteien sowie den Schiedsrichtern beigemessen wurde. Eine schriftliche Vollmacht beispielsweise nützte nur, wenn sich der Beglaubigte auch daran gebunden fühlte. Nur Schriftstücke, die z.B. im Hinblick auf ihren Aussteller als verbindlich erachtet wurden, konnten ihre Wirkkraft als Beweis- oder Legitimationsmittel entfalten. So verlor ein Brief des Kaisers, das machte dessen Anwalt deutlich, seine Kraft, wenn die Handlung, die er legitimieren sollte, als Rechtsbruch einzustufen war.

Ihre größte Schwäche zeigte Schriftlichkeit schließlich im Angesicht der Übermacht des Faktischen. Einlassbriefe nützten nichts, blieben Stadttore verschlossen. Schriftliche Belege waren unbrauchbar, wenn sie von der gegnerischen Partei oder dem Schiedsgericht ignoriert wurden. In letzter Konsequenz richteten auch schriftlich fixierte Schiedsurteile nichts aus, wenn sich die Parteien nicht daran hielten. Friedrich III. konnte mit den Verfahrensprotokollen weder gegen Václav Vlček ins Feld ziehen noch Andreas Weispriach davon abhalten, zum König von Ungarn überzulaufen. Zumindest in dieser Hinsicht waren beide Schiedsverfahren als Maßnahme zur Konfliktbewältigung gescheitert. 


\section{Žold a ztráta: Císař (si) vyřizuje účty. Úvahy o dvou rozhodčích procesech mezi císařem Fridrichem III. a veliteli žoldnéřů v době uherské války}

Počátkem roku 1482 císař Fridrich III. a jeho tehdejší dva nejdůležitější velitelé žoldnéřủ (Václav Vlček z Čenova a Ondřej z Weispriachu a na Kobelsdorfu) vedli spor před rozhodčím soudem o uznání svých nároků. Žoldnéři, které císař najal do války proti králi Matyáši Korvínovi, požadovali zaplacení žoldu a nahrádu utrpěných škod. Naopak císař jako nejvyšší zeměpán podal na oba žalobu a dožadoval se zadostiučinění za škody způsobené žoldnéři v jeho dědičných zemích.

Analýza procesních protokolů ukazuje, že písemnosti hrály v průběhu překonávání konfliktu poměrně důležitou a také všestrannou roli. Písemnosti omezovaly a současně otevíraly prostor pro jednání, sloužily oběma stranám jako podpora pro jejich argumentaci, určovaly strukturu celého procesu a samy se stávaly předmětem jednání. Přitom byly pragmatické písemnosti, které vznikaly v průběhu vykonávání žoldnéřských povinností, stejně relevantní jako samotný rozhodčí proces se svým vlastním způsobem zpísemňování.

Nebylo vůbec samozřejmé, že k vyřešení konfliktu byl v obou případech zvolen právě rozhodčí proces. Friedrich III. totiž jako strana v rozhodčím procesu vystupoval dosud velmi zrrídka. Pohled na historický kontext rozhodčího procesu, podoba smírčích smluv a v neposlední řadě volba rozhodčích soudců ukazuje, že proces byl iniciován na císařském dvoře a byl veden podle záměrů císaře. Pro Fridricha III., který během své vlády instrumentalizoval soudnictví k prosazování svých záměrů, se rovněž tyto rozhodčí procesy staly prostředkem k tomu, aby se na jedné straně vyvázal z finančních závazků vưči žoldnéŕům, a aby si na straně druhé zachoval svou autoritu vưči žoldnéřo̊m jako zeměpán a vládce. 